\title{
Water uptake study of anion exchange membranes
}

Yiwei Zheng, ${ }^{1}$ Uri Ash, ${ }^{1}$ Ravi P. Pandey, ${ }^{1}$ Amobi G. Ozioko, ${ }^{3}$ Julia Ponce-González, ${ }^{5}$

Michael Handl, ${ }^{4}$ Thomas Weissbach, ${ }^{6}$ John R. Varcoe, ${ }^{5}$ Steven Holdcroft, ${ }^{6}$ Matthew W. Liberatore ${ }^{3}$ Renate Hiesgen, ${ }^{4}$ Dario R. Dekel ${ }^{1,2}$

${ }^{1}$ The Wolfson Department of Chemical Engineering, Technion - Israel Institute of Technology, Haifa 3200003, Israel

${ }^{2}$ The Nancy \& Stephan Grand Technion Energy Program (GTEP), Technion - Israel Institute of Technology, Haifa 3200003, Israel

${ }^{3}$ Department of Chemical Engineering, University of Toledo, Toledo, OH 43606, U.S.A.

${ }^{4}$ Hochschule Esslingen - University of Applied Sciences, 73728 Esslingen, Germany

${ }^{5}$ Department of Chemistry, University of Surrey, Guildford, GU2 7XH, UK

${ }^{6}$ Department of Chemistry, Simon Fraser University, 8888 University Drive, Burnaby, BC, V5A 1S6, Canada

\begin{abstract}
Anion exchange membrane fuel cells (AEMFCs) have attracted extensive attention in the recent years, primarily due to the distinct advantage potentials they have over the mainstream proton exchange membrane fuel cells. The anion exchange membrane (AEM) is the key component of AEMFC systems. Due to the unique characteristics of water management in AEMFCs, understanding the water mobility through AEMs is
\end{abstract}


key for this technology, as it significantly affects (and limits) overall cell performances. This work presents a study of the equilibrium state and kinetics of water uptake (WU) for AEMs exposed to vapor source $\mathrm{H}_{2} \mathrm{O}$. We investigate different AEMs that exhibit diverse water uptake behaviors. AEMs containing different backbones (fluorinated and hydrocarbon-based backbones) and different functional groups (various cations as part of the backbone or as pendant groups) were studied. Equilibrium WU isotherms are measured and fitted by the Park model. The influence of relative humidity and temperature is also studied for both equilibrium and dynamic WU. A characteristic time constant is used to describe WU kinetics during the $\mathrm{H}_{2} \mathrm{O}$ sorption process. To the best of our knowledge, this is the first time that WU kinetics has been thoroughly investigated on AEMs containing different backbones and cationic functional groups. The method and analysis described in this work provides critical insights to assist with the design of the next generation anion conducting polymer electrolytes and membranes for use in advanced, high-performance AEMFCs.

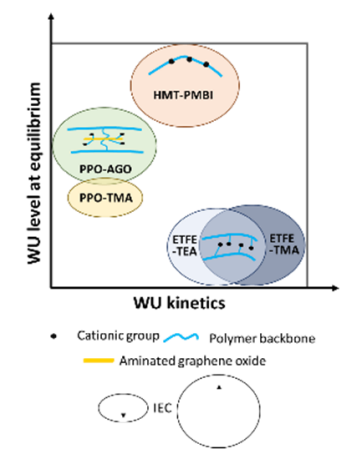

\section{Introduction}

Anion-exchange membrane fuel cells (AEMFCs) represent a new generation of 
potentially disruptive, low temperature fuel cell technology with the potential to eliminate the main cost barriers of the mainstream proton-exchange membrane fuel cells (PEMFCs). ${ }^{1}$ In the anion exchange membranes (AEMs), the core component of AEMFCs, positively charged (cationic) functional groups (FGs) allow the transport of anions (e.g. $\left.\mathrm{Cl}^{-}, \mathrm{OH}^{-}\right)$through the membrane. ${ }^{2}$ Quaternary ammonium groups (for instance, benzyltrimethylammonium, $N$-methylpyrrolidinium, etc.) are widely used as FGs in currently developed AEMs.,

The most important performance characteristics of AEMs for FC applications are anion conductivity and water mobility. Both properties are directly linked to each other. Figure 1 summarizes the extensive conductivity and water uptake (WU) data that has been collected on AEMs that were submerged in liquid water (and not in contact with vapor state $\left.\mathrm{H}_{2} \mathrm{O}\right){ }^{5-59}$ Similarly to a parallel report for proton-exchange membranes (PEM) by Kim et $a l .{ }^{46}$, increases in the membrane conductivities of AEMs generally correlates with increasing WUs. Conductivity values seem to reach a plateau at $\sigma \approx 0.1$ $\mathrm{S} / \mathrm{cm}$ (Figure 1). For AEMs in the $\mathrm{Cl}^{-}$anion forms with ion exchange capacity (IEC) of $c a .1 .5 \mathrm{meq} / \mathrm{g}$, this plateau is close to the intrinsic conductivity value of the $\mathrm{Cl}^{-}$anion in dilute aqueous solution. ${ }^{60}$ The increase in conductivity with increasing $\mathrm{WU}^{61}$ is not the only benefit of keeping AEM well hydrated in an AEMFC. We have recently shown that AEMFCs are prone to cathode dry-out during cell operation at high current densities, ${ }^{62}$ an effect that may be counter-balanced or alleviated by using an AEM with a high hydration number (the number of water molecules per FG). 


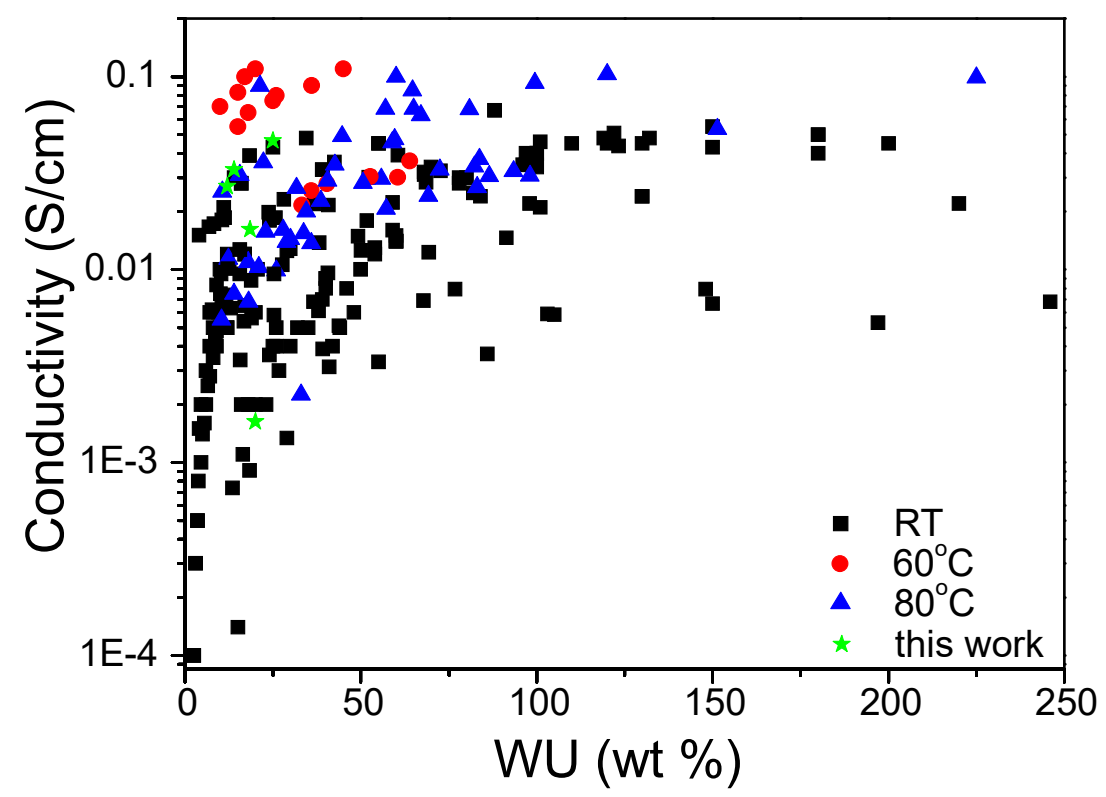

Figure 1. Conductivity as a function of water uptake from liquid water of AEMs at room temperature $\left(\mathrm{RT}, 20-30{ }^{\circ} \mathrm{C}\right), 60{ }^{\circ} \mathrm{C}$ and $80{ }^{\circ} \mathrm{C}$. Adopted from refs. ${ }^{5-59}$ The conductivities $^{\dagger}$ of the AEMs used in this work were also added to aid comparison.

In contrast to the case where an AEM is immersed in liquid water (see data summarized in Figure 1), exposing the AEMs to atmospheres containing different relative humidities (RH) will lead to a variation in the corresponding WU levels (and hydration numbers). The conductivity, mechanical properties and the physical dimensions of an ionomeric membrane are functions of such $\mathrm{H}_{2} \mathrm{O}$ content, making this an important, independent parameter for AEM design. ${ }^{6,64}$ The equilibrium water uptake at a given RH is referred hereafter as WU or WU equilibrium. For AEMFC applications, the WUs resulting from sorption of $\mathrm{H}_{2} \mathrm{O}$ from the vapor phase, rather than sorption from liquid water, is of interest since water is supplied to the cell in the form of humidified gases. Figure 2 depicts a general scheme showing the important forms of water transport in 
an operating AEMFC. 


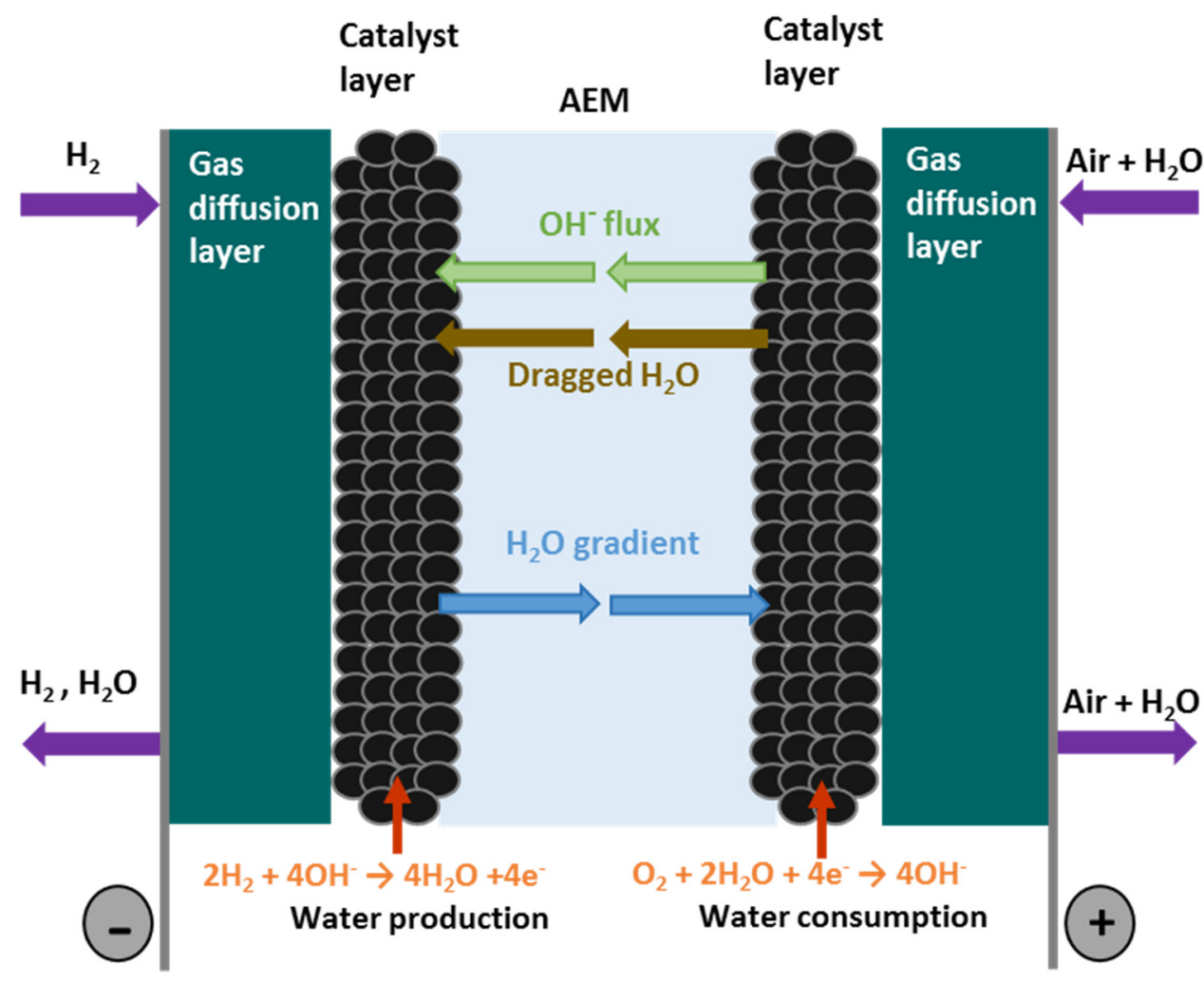

Figure 2. Schematic diagram of an operating single cell AEMFC system.

In parallel to this significance of high WU, fast water transport across the AEM is also critical to obtaining high AEMFC performance, since the actual operating conditions will change the water content within the AEM. Startup, shutdown, changes in the cell load and environmental alterations of relative humidity and temperature will rapidly affect the water distribution within the cell. ${ }^{65} \mathrm{~A}$ fast adjustment of the water content within the AEM (and anion-exchaneg ionomer located in the electrodes' catalyst layers) in response to these variations will enhance the cell performance and performance stability. Recording the temporal WU response to $\mathrm{RH}$ step-changes yields the 
membrane's dynamic WU for the study of kinetics. ${ }^{66}$ Very few AEM studies have focused on WU from water vapor. ${ }^{66-71}$ In the previous studies that look at the WU of AEMs as a function of the $\mathrm{RH}$, a RH range of $20 \%-95 \%$ was typically used.

Ponce-Gonzalez et al. synthesized radiation-grafted poly(ethylene-cotetrafluoroethylene)-g-polyvinylbenzyl-(PVB)-based membranes that contained different FGs. The authors compared the WU of the different AEMs with increasing RH and found that AEMs with N-methylpiperidinium (MPRD)-methylpyrrolidinium (MPY) HGs have similar WUs $<40 \%$ RH, while PVB-MPRD showed larger WUs at higher RHs. ${ }^{70}$ They concluded that the higher WU levels allowed by the through-plane swelling of the MPRD-AEM, resulted in a slightly lower anion conductivity.

While these studies provide useful data on the WU from water vapor at different RHs, none of them investigated the kinetics of the WU. To the best of our understanding, there have been only two prior studies reporting the WU kinetics characteristics of fuel cell relevant AEMs. ${ }^{66,72}$ Follain et al. examined the influence of plasma-modification on the water sorption and diffusion properties of a commercial AEM by increasing RH. The authors found that the plasma-treated (crosslinked) membranes had slower sorption kinetics than non-crosslinked membranes. ${ }^{66}$ Mangiagli et al. compared the WU kinetics of one poly(arylene ether sulfone) based AEM to various PEMs and investigated the $\mathrm{H}_{2} \mathrm{O}$ sorption time constant as a function of $\mathrm{RH}$. They found that at the kinetics of sorption was more rapid at low $\mathrm{RH}$ compared to when the $\mathrm{RH}$ was raised. ${ }^{72}$

While the above studies provide initial and important data on WU kinetics, a thorough investigation on both the equilibrium WU and the kinetics of WU of AEMs, including 
the study of the effect of different fuel cell relevant parameters (temperature, RH, etc.) is missing. Herein, we present a thorough characterization of equilibrium WU and WU kinetics for three different types of AEM, including the effects of temperature and relative humidity. The equilibrium WU results were analyzed by fitting water absorption isotherms using the Park model. In addition, we analyzed the WU kinetics over a wide range of $\mathrm{RH}$ values and temperatures, and summarized the characteristic parameters of WU dynamics for the different AEMs. To the best of our knowledge, this is the first time this type of WU kinetic study on AEMs has been presented. This study is further complemented with microscopic AFM characterization and mechanical testing. The results of this study will help to establish appropriate characterization methods, that are relevant to functional AEMs, and increase the understanding of the processes governing WU in these polymer electrolytes. 


\section{Experimental}

\section{Anion exchange membranes}

PPO-based membranes. Two types of poly(phenylene oxide) membranes were studied: non-crosslinked (denoted as PPO-TMA, Figure 3(a)) and crosslinked with aminated graphene oxide (AGO) (denoted as PPO-AGO, Figure 3(b)). Commercial PPO (Sigma-Aldrich) was dissolved, brominated and then aminated with trimethylamine. The resulting solution was cast onto a clean glass plate and dried to produce the anion conducting PPO membrane. The AGO was prepared by oxidizing graphite to graphene oxide, silanizing it with $(N, N$ dimethylaminopropyl)trimethoxysilane, chlorinating the latter with thionyl chloride and finally aminating it with trimethylamine. The brominated PPO was then crosslinked with the AGO, cast onto a clean glass plate and dried to obtain an anion conducting crosslinked PPO. Detailed description is provided in the Supporting Information.

HMT-PMBI membranes. Composed of 2,2",4,4",6,6"-hexamethyl-p-terphenylene (HMT) and N-methylated poly(benzimidazolium)s (PMBI), a 89.3\% degree of methylation (dm) HMT-PMBI-I- membrane was prepared, as described in detail elsewhere. ${ }^{73}$ The cationic functional groups in this membrane are part of the polymer backbone (Figure 3(c)), rather than tethered along the backbone as in PPO-based AEMs. Preparation procedure of HMT-PMBI-OH ${ }^{-}$is reported elsewhere. ${ }^{73}$ The film was prepared via casting from DMSO at $80{ }^{\circ} \mathrm{C}$, soaked in $\mathrm{H}_{2} \mathrm{O}$ for $24 \mathrm{~h}$, and dried under vacuum at $80{ }^{\circ} \mathrm{C} .^{73}$ 
ETFE-based membranes. Vinylbenzyl chloride monomer (VBC) was radiationgrafted onto ETFE films to form intermediate grafted membranes (ETFE-g-VBC) as described in detail previously. ${ }^{74}$ These intermediate grafted membranes were then quaternized with trimethylamine (denoted hereafter as ETFE-TMA, Figure 3(d)) and triethylamine (ETFE-TEA, Figure 3(e)). ${ }^{74}$

All AEMs used in this study were in the chloride form. AEMs were immersed in $1.0 \mathrm{M}$ $\mathrm{KCl}$ solution for $48 \mathrm{~h}$ and the solution was changed three times to exchange the halide ions.

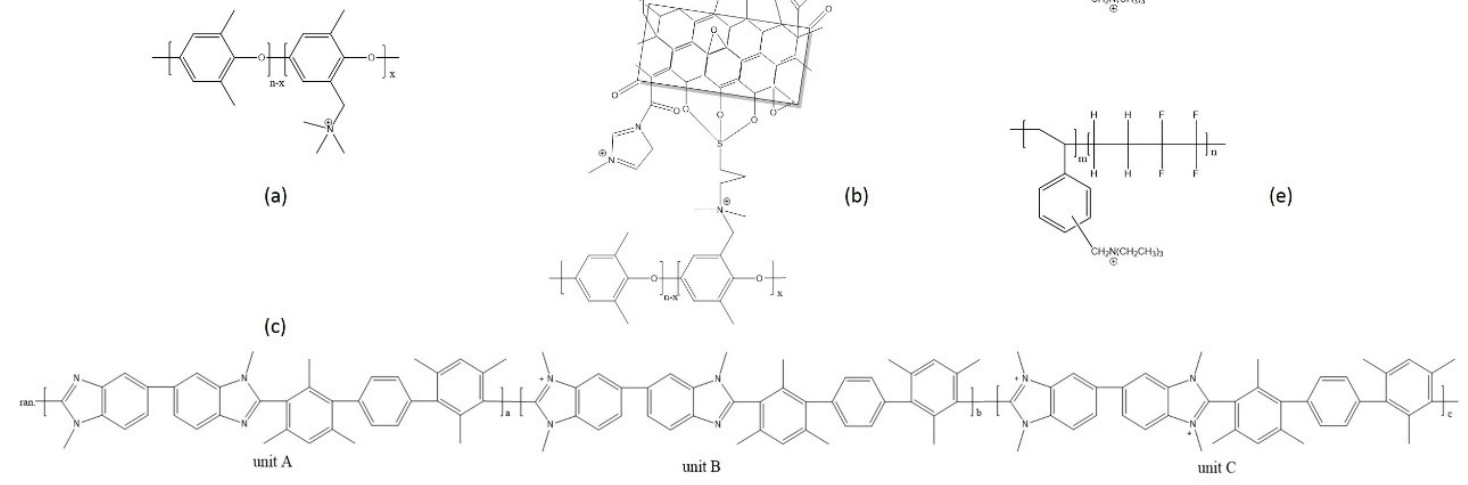

Figure 3. The structures of (a) PPO-TMA (b) PPO-AGO (c) HMT-PMBI (d) ETFETMA and (e) ETFE-TEA anion exchange membranes.

\section{WU measurements}

WU equilibrium. The WU was measured using a VTI SA ${ }^{+}$instrument (TA Instruments, USA). The RH was determined with a two-stage chilled-mirror dew-point analyzer and adjusted by mixing dry and humidified nitrogen gas. Each sample was initially dried 
in-situ for maximum 60 min at $60{ }^{\circ} \mathrm{C}$ and $\mathrm{RH} \approx 0 \%$. $\mathrm{RH}$ was step-changed in intervals of 5\%,10\% and 20\%. Each RH step was maintained until the sample weight reached equilibrium $(<0.001 \mathrm{wt} \%$ change in $5 \mathrm{~min})$. WU is calculated from the 'wet' weight $[\mathrm{W}($ wet $)]$ at each equilibrium and the 'dry' weight $[\mathrm{W}($ dry $)]$ at the end of the initial drying step, according to: ${ }^{8}$

$$
\mathrm{WU}=\frac{W(w e t)-W(d r y)}{W(d r y)} \times 100 \%
$$

WU kinetics. The WU kinetics was measured by following the mass change of the AEM as a function of time, as a result of the applied RH step. The characteristic time constant, $\tau$, was calculated by fitting the experimental data with the following: ${ }^{75}$

$$
\frac{W_{t}-W_{0}}{W_{\infty}-W_{0}}=\frac{M_{t}}{M_{\infty}} \cong 1-\exp \left(-\frac{t}{\tau}\right)
$$

where $\mathrm{W}_{\mathrm{t}}$ is the mass of sample at time $\mathrm{t}, \mathrm{W}_{0}$ is the mass at the beginning of the $\mathrm{RH}$ step, $\mathrm{W}_{\infty}$ is the mass of membrane at equilibrium state, $M_{t}$ is the mass gain at time $\mathrm{t}$, $M_{\infty}$ is the mass gain of membrane at equilibrium state.

IEC measurements. IEC was determined by titration using a Metrohm titrator. A 1.0 $\mathrm{M} \mathrm{KCl}$ solution exchanged the anions in the samples for $48 \mathrm{~h}$. The excess $\mathrm{Cl}^{-}$(and $\mathrm{K}^{+}$) ions were removed via washing with deionized water for $48 \mathrm{~h}$. The $\mathrm{Cl}^{-}$now present as a counter-anion in the membrane was displaced into a $1.0 \mathrm{M} \mathrm{KNO}_{3}$ solution for $48 \mathrm{~h}$. This solution (without the membrane) was titrated with $0.01 \mathrm{M} \mathrm{AgNO}_{3}$ to determine 
the $\mathrm{Cl}^{-}$concentration (using a Ag-titrode to detect the titration end-point). The AEM was further washed in deionized water, dried in vacuum oven (3-4 h) and weighed. IEC is expressed as millimoles of $\mathrm{Cl}^{-}$per gram of dry membrane (meq/g): ${ }^{.5}$

$$
\mathrm{IEC}=\frac{\Delta \mathrm{AgNO}_{3} \mathrm{C}_{\mathrm{ANO}_{3}}}{W(d r y)}
$$

where $\Delta \mathrm{V}_{\mathrm{AgNO}_{3}}$ and $\mathrm{C}_{\mathrm{AgNO}_{3}}$ are the end point volume $\left(\mathrm{cm}^{3}\right)$ and concentration $(\mathrm{M})$ of the titrant solution, respectively, and W(dry) is the mass of the dry membrane. IEC is further used to calculate the hydration number $(\lambda)$, the number of water molecules per FG:

$$
\lambda=\frac{w / M W}{I E C \times W(d r y)}
$$

where $\mathrm{w}$ is the measured mass of water $(\mathrm{g}), \mathrm{MW}$ is the molecular weight of water $(\mathrm{g} / \mathrm{mol})$

\section{Mechanical Characterization}

Mechanical properties of polymer films were determined using an ARES G2 rheometer (TA Instruments, US) with a Sentmanat Extension Rheometer (SER) fixture (Xpansion Instruments). Details on the experimental system have been previously published in detail available ${ }^{76}$ and are summarized here. The AEM samples are attached to the SER fixture, which has two counter rotating drums with custom-designed clamps that stretch the films in a uniaxial manner to failure. Membranes were stretched at a Hencky strain 
rate of $0.033 \mathrm{~s}^{-1}$. The stress at break is described as the magnitude of stress applied to the film just before breaking. The percent elongation is the percent increase observed in AEM length. The Young's modulus quantifies the elastic nature of the membrane, which was obtained from the slope of a stress-strain curve in the elastic region(i.e. at very low strains).

The AEMs under study were cut into strips of about $4 \mathrm{~mm}$ (width) by $20 \mathrm{~mm}$ (length) for testing. Membrane thickness ranged from $60 \mu \mathrm{m}$ to $130 \mu \mathrm{m}$. The SER drums were wrapped with double-stick, high temperature tape to prevent film slippage. Screw-down pins were used to secure the film to the drum surface; tape was also placed over the outer edges of the film, outside the sample area to further reduce slip. Dry conditions were achieved using the Forced Convection Oven (FCO) airflow system available for the ARES. Humidified, $60{ }^{\circ} \mathrm{C}$ conditions were achieved by combining dry and wet air streams supplied to a custom-built humidity oven. The humidified tests were allowed a soak time of at least $30 \mathrm{~min}$ before testing began in order to allow for adequate humidification of the membranes. A Vaisala HMT337 humidity probe was used to provide real time feedback of the humidity conditions within the oven to the LabView software where the gas flows were controlled.

\section{AFM measurement}

Cross-sections of the membranes investigated by AFM were prepared by microtome using a glass knife, after embedding with a two-component epoxy resin (Araldite 502 with dodecenyl succinic anhydride, cured for $16 \mathrm{~h}$ at $60{ }^{\circ} \mathrm{C}$ ). The cross-sections were fixed on a steel sample disc by double-sided conductive adhesive tape, which was 
impregnated with Pt nanoparticles (Sigma Aldrich, diameter $<50 \mathrm{~nm}$ ). Prior to all AFM measurements, the AEM cross-sections were equilibrated for at least $2 \mathrm{~h}$ at the respective $\mathrm{RH}$. The accuracy of the $\mathrm{RH}$ adjustment was $\pm 5 \%$. AFM measurements were performed with a Multimode 8 AFM (Bruker) equipped with an environmental chamber for controlled relative humidity. The temperature inside the measurement chamber was $(30 \pm 2){ }^{\circ} \mathrm{C}$. Nano-mechanical properties were measured by the Peak Force QNM ${ }^{\circledR}$ mode. 


\section{Results and discussion}

WU equilibrium
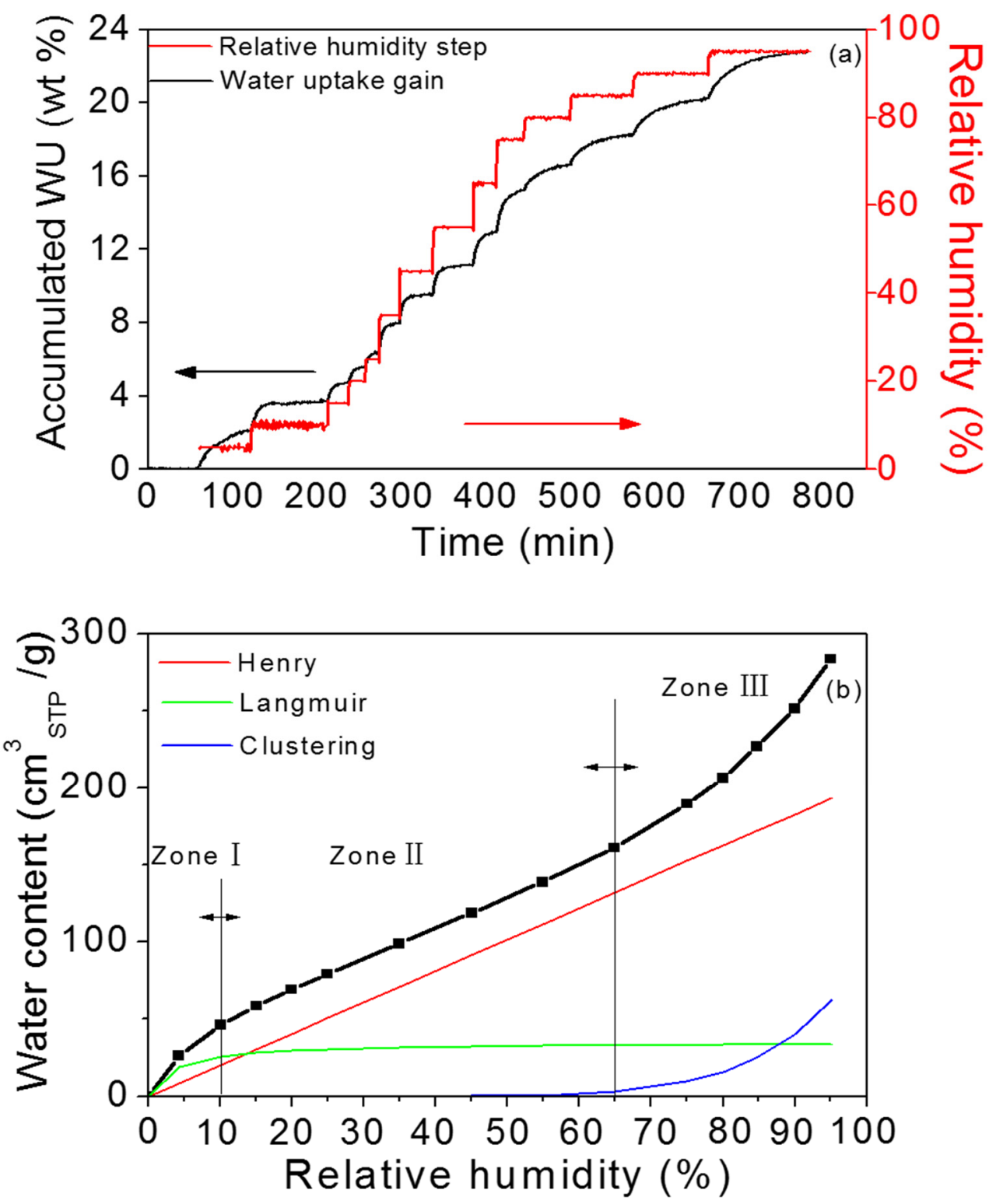

Figure 4 (a) WU mass gain (black, left y-axis) during a typical water-vapor absorption experiment for HMT-PMBI membrane at $30{ }^{\circ} \mathrm{C}$. The corresponding relative humidity is shown in red (right y-axis). These data are reproduced in the lower figure - (b) water content of the membrane $\left(\mathrm{cm}^{3} \mathrm{STP} / \mathrm{g}\right.$, black dots) versus the corresponding relative 
humidity (\%). Black line is the Park model fitting; the colored curves are its three individual components. $^{77}$

We measured the WU of the membranes via their mass gain at different RH levels.

Figure 4(a) shows the accumulated WU of HMT-PMBI during step changes in RH. Both the WU (relative to the dry membrane) and the RH levels are shown versus the experimental time. As the RH increases, the membrane absorbs more water and its mass increases accordingly. At each RH step, the membrane was allowed to equilibrate, and the next step started once the membrane mass had stabilized $(<0.001 \mathrm{wt} \%$ change in 5 min). The WU equilibrium points at each corresponding $\mathrm{RH}$ are reproduced in

Figure 4(b) (black curve). The WU is presented as the calculated water content of the membrane, which is able to unify the WU values at different temperatures. As can be seen, at low RH levels, in the RH step from $0 \%$ to $5 \%$, the highest increase in water content is achieved. As RH increases from $5 \%$ to $10 \%$, the WU increase per step becomes smaller. At medium RH levels (10\%-65\%) the increase in WU with RH is linear. Above RH of $65 \%$, the WU increases exponentially with RH. These results are fitted by the Park model ${ }^{77-79}$, which comprises three separate sub-models: Langmuir, Henry and clustering for low, medium and high RH values, respectively. The individual contribution of each sub-model is also presented in

Figure 4(b), in the separately colored curves.

The Henry-type absorption, which contributes to the whole $\mathrm{RH}$ range, is the only relevant contribution to the medium RH zone (noted as Zone II). The other two types 
of absorption contributions are valid either at low- or high-RH zones (Langmuir and clustering, noted as Zone I and Zone III, respectively). Therefore, for each AEM, we first fitted the linear increase in zone II to Henry's equation, and then subsequently determined the zones of relevance to the Langmuir and clustering contributions. The end of Langmuir-type absorption zone was set to the point where Henry's linear increase begins. Similarly, the starting of the clustering zone was set to the end of the linear-only zone.

The absorption isotherm in

Figure $4(b)$ is similar in shape to the few isotherms previously published for other AEMs. ${ }^{42,66,69-72,80,81}$ Equilibrium water uptake in such membranes was previously modeled by the Park model ${ }^{77-79}$ and by the New Dual Mode Sorption (NDMS) model ${ }^{82}$, since both are usually applied to simulate water sorption in hydrophilic polymer materials. Nevertheless, since NDMS does not simulate the monolayer described by Langmuir's type sorption at low RH, the Park model provides a better fit. In principle, Park model describes three types of water absorption (Langmuir, Henry and clustering), which can be fitted by five adjustable parameters (Table S1). Previously reported Park model fitting has led to poor accuracy of the Langmuir parameters, due to lack of data below $20 \% \mathrm{RH}^{77-79}$ Here, we achieved very low $\mathrm{RH}$ values to improve the accuracy of Park model fitting.

The Langmuir equation (see Supporting Information) describes the formation of a monolayer of water molecules. They reside in the hydration layer around the anions and alkali groups due to the strong interactions caused by hydrogen bonds. As the 
relative humidity increases, molecules are absorbed by an ordinary dissolution mechanism (Henry's model). Rapid WU increase in the convex part from the line upturn to highest RH is indicative of the formation of bulk water clusters. This phenomenon was previously attributed to the flexibility of the membrane matrix and its affinity for water. $^{83}$

The membranes investigated herein are built from different polymeric backbones, with different quaternary ammonium FGs. These differences are expected to affect their WU values. In Figure 5(a), the equilibrium water content at $30^{\circ} \mathrm{C}$ of all selected AEMs HMT-PMBI, PPO-TMA, PPO-AGO and ETFE (TMA and TEA) - is presented versus the RH at each step. All data were fitted by using the Park model, as previously discussed. HMT-PMBI stands out from the other membranes with the highest water content value, roughly twice as much as the radiation-grafted ETFE-based AEMs: $25 \%$ versus $12 \%$ at $\mathrm{RH}=65 \%$, respectively. Also below this $\mathrm{RH}$, HMT-PMBI membrane absorbs much more water than other membranes used in this study. This is probably due to the fact that the HMT-PMBI membrane has a higher IEC compared to the other AEMs (Table 1). However, the clustering WU contribution of HMT-PMBI is comparable to the PPO-based membranes, (corresponding clustering parameters can be seen in Table S1). The very different structures of the two AEM types, as well as their different IECs, may be the reason for this behavior. The PPO-based membranes show WU levels slightly higher than ETFE-based AEMs. PPO-AGO absorbs more water than its non-crosslinked counterpart does. This is reasonable, considering the twice-higher IEC and the structure of PPO-AGO, where the PPO backbone is crosslinked by an ionic 
hydrophilic crosslinker. This may create a larger space volume for water absorption, and specifically enhance the formation and existence of clustering. The latter is supported by the larger clustering parameter of PPO-AGO and hydrophilic/water-rich clusters at the boundaries of the AGO crosslinker at $80 \% \mathrm{RH}$, as was observed by AFM (Figure S3(b)). For the two ETFE-based AEMs, the difference in the QA groups (TMA versus TEA) is expected to have minor influence on WU. ETFE-TMA absorbed slightly more water compared to ETFE-TEA at all RH levels, which is expected due to the $43 \%$ higher IEC of ETFE-TMA.

Table 1. Average IEC values of the different membranes

\begin{tabular}{|c|c|c|c|c|c|}
\hline & HMT-PMBI & PPO-AGO & PPO-TMA & ETFE-TMA & ETFE-TEA \\
\hline IEC (meq/g) & 2.17 & 1.25 & 0.66 & 1.85 & 1.29 \\
\hline
\end{tabular}

The hydration number $\lambda$ has been widely used to describe water content from water vapor sorption in order to study water transport ${ }^{42}$ and molecular dynamics modeling ${ }^{84}$ of various AEM materials. Because $\lambda$ presents the number of water molecules per FG, the use of hydration number could avoid some of the limitations of mass-based WU. ${ }^{46}$ Figure 5(b) shows $\lambda$ versus RH for all the studied membranes. PPO-TMA shows the highest $\lambda$ compared to the other AEMs, owing to its low IEC (Table 1). From a different point of view, the low IEC may allow larger distances between neighboring FGs, thus facilitating full hydration for each QA. This may also be the case for PPO-AGO, which presents $\lambda$ similar to HMT-PMBI, in spite of its lower water content: not only it has the 
second lowest IEC, but also some FGs are located on the crosslinking spacers.
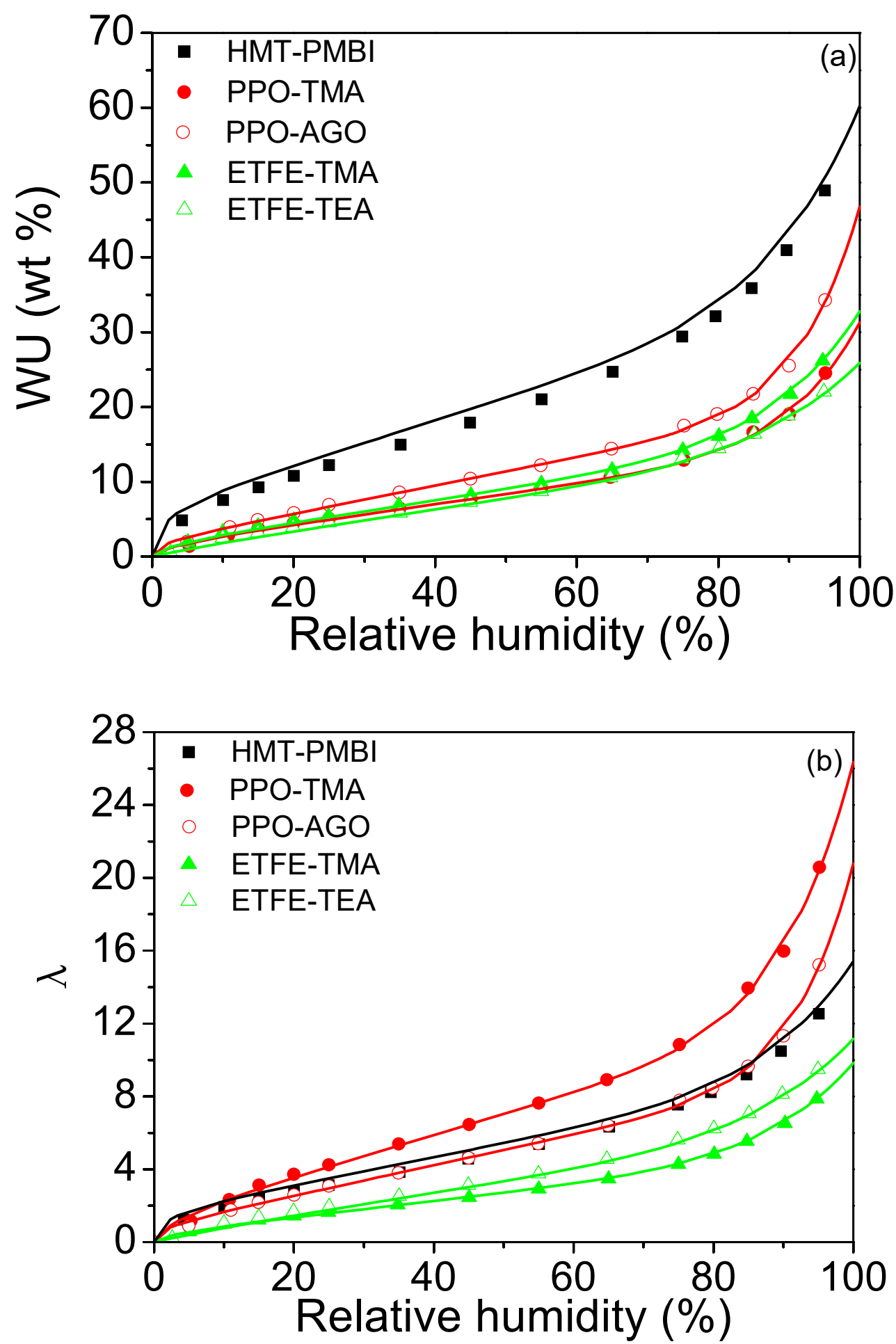

Figure 5. Water vapor absorption isotherms for HMT-PMBI, PPO-TMA, PPO-AGO, ETFE-TMA and ETFE-TEA membranes at $30{ }^{\circ} \mathrm{C}$. The amount of absorbed water is 
expressed as (a) water content, and (b) $\lambda$. Solid lines are Park model fitting.

Mechanical properties. The stress-strain characteristics of HMT-PMBI, PPO-TMA and PPO-AGO changed between drier and wetter conditions at $60{ }^{\circ} \mathrm{C}$, which agrees with other AEMs and PEMs. ${ }^{76,85-89}$ By using two different humidities, the range of mechanical properties of a film can be captured within the context of the water uptake study; a more exhaustive study ${ }^{81}$ was not completed as it is outside of the scope of this work. The mechanical properties of ETFE-TMA were studied previously and qualitatively agree with the changes with water content discussed here. ${ }^{88}$ The Young's modulus, shown in Figure 6(a), decreased from dry to wet conditions indicating weakening of films with increasing humidity. HMT-PMBI membrane showed the most dramatic change of over $55 \%$ decrease from $1010 \mathrm{MPa}$ to about $440 \mathrm{MPa}$ between 25 and $90 \%$ RH. PPO-TMA showed over 25\% decrease in Young's modulus from 400 to $290 \mathrm{MPa}$ at elevated humidity compared to dry conditions. PPO-AGO modulus decreased over $50 \%$ from $20 \mathrm{MPa}$ to about $8 \mathrm{MPa}$ from dry to wet conditions. The decrease in Young's Modulus at wet conditions is in agreement with previous results for HMT-PMBI-based AEMs. ${ }^{85}$ Comparing these changes in Young's modulus to the equilibrium water content (Figure 5(a)), the largest water content was measured for HMT-PMBI, which also showed the largest percent change in Young's Modulus. 

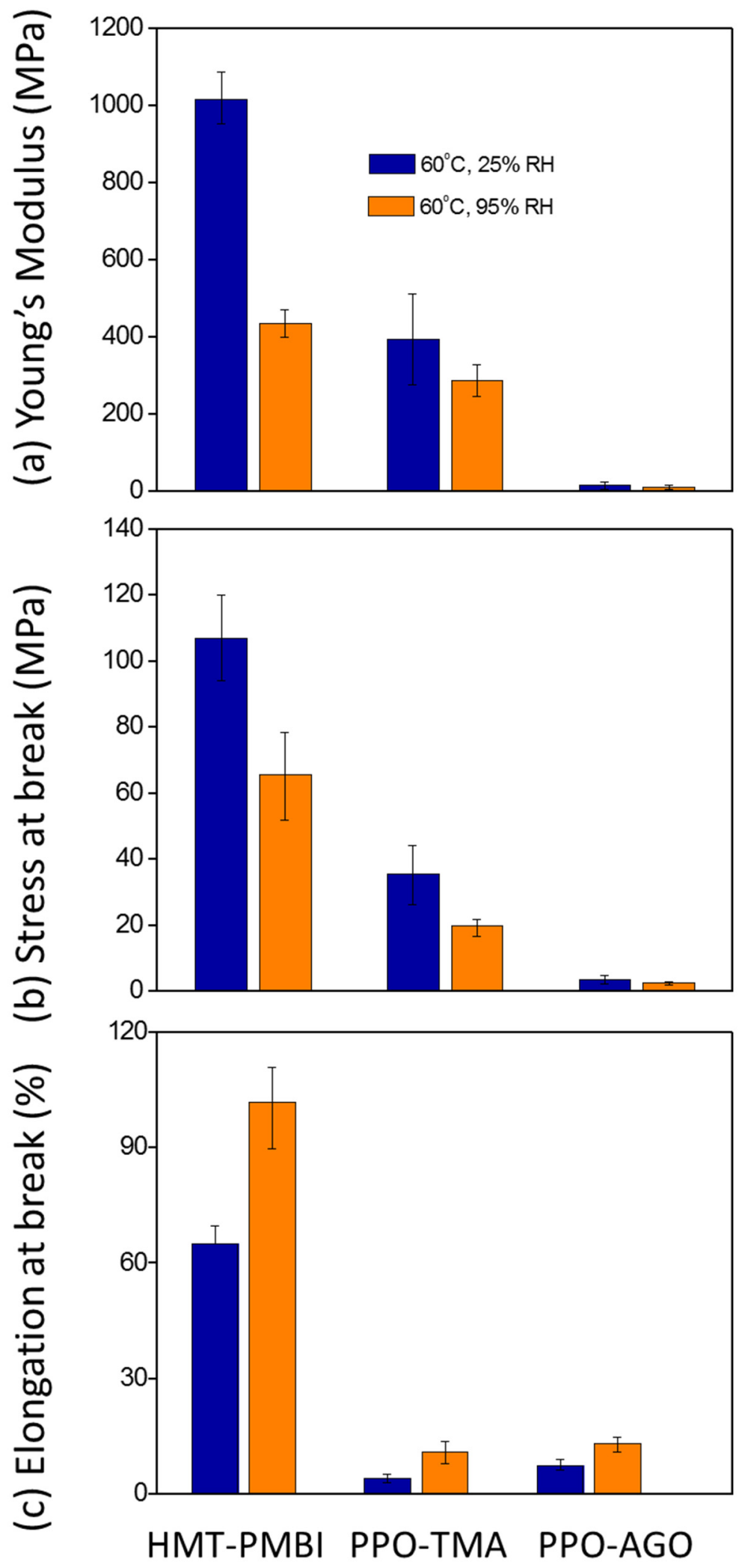

Figure 6. (a) Young's modulus (MPa), (b) stress at break (MPa) and (c) Elongation (\%) for HMT-PMBI, PPO-TMA and PPO-AGO under low and high relative humidity. 
Similar to Young's modulus, the stress at break, in Figure 6(b), decreased about 40-60\% with increasing humidity. Stress at break values for HMT-PMBI and PPO-TMA membranes decreased about 40\%. PPO-AGO showed the lowest stress at break values of about $2 \mathrm{MPa}$ at dry conditions and $1 \mathrm{MPa}$ at wet conditions. The decrease in the stress at break at wet conditions is also in agreement with previous results for HMTPMBI. ${ }^{85}$

Membrane elongation in Figure 6(c) showed an opposite trend to Young's modulus and strength, and increased with increasing humidity (as the AEMs become more rubbery in nature on hydration). Percentage elongation ranged from 4 to $12 \%$ for the dry films changing from 5 to $38 \%$ for the wet films. HMT-PMBI membrane increased over $50 \%$ from $64 \%$ percent elongation at dry conditions to $99 \%$ percent elongation at wet conditions; PPO-TMA increased significantly from $~ 5 \%$ percent elongation to $12 \%$. Similarly, PPO-AGO percent elongation increased from about 7\% to $13 \%$. Previously, HMT-PMBI was reported to have a decrease in elongation in the wet form at room temperature. ${ }^{85}$ The largest increase in percent elongation was measured for the HMTPMBI membrane, which also had the largest water content (Figure 5(b)), while similar changes in percent elongation for bother PPO-based membranes correlates with similar water content changes.

Additional mechanical and structural properties, investigated by AFM, allowed an interesting insight into the sublayers of some AEMs. The AFM measurements focused at the interface between the HMT-PMBI membrane and the embedding epoxy material. It showed no difference in mechanical properties between the membrane's edge and its 
regular surface, indicating that the subsurface of the membrane is of the same composition as the surface itself, and the membrane is homogeneous. The dependence of membrane height above the epoxy on different RH is illustrated in Figure 7, where the $3 \mathrm{D}$ topography images were additionally colored by adhesion force mapping. The adhesion force becomes stronger in wet membranes. With increasing $\mathrm{RH}$ and membrane swelling, the difference in adhesion force between the epoxy and the membrane became more pronounced (Figure 7(d)). Both results indicate homogeneous WU when increasing RH. As no hydrophobic interface is detectable, a relatively quick WU into the HMT-PMBI is expected, which is consistent with kinetics results shown below.

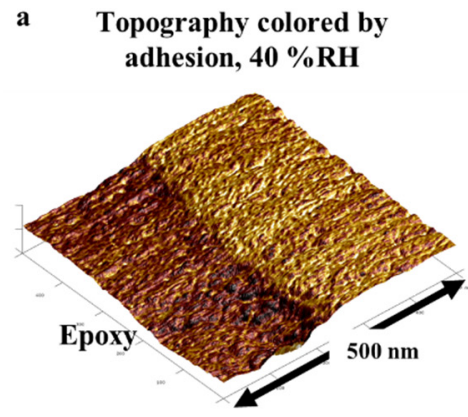

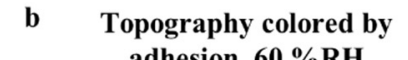

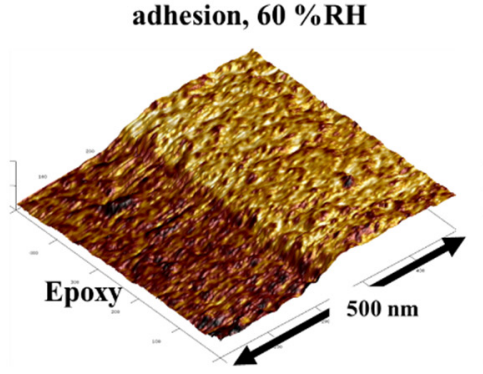

c Topography colored by adhesion, $80 \%$ RH

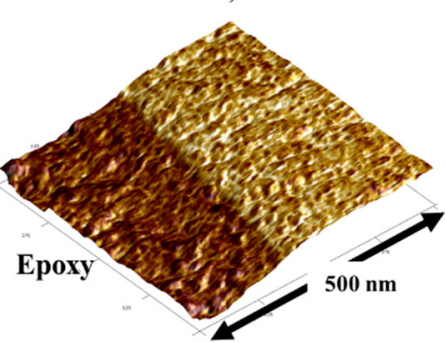

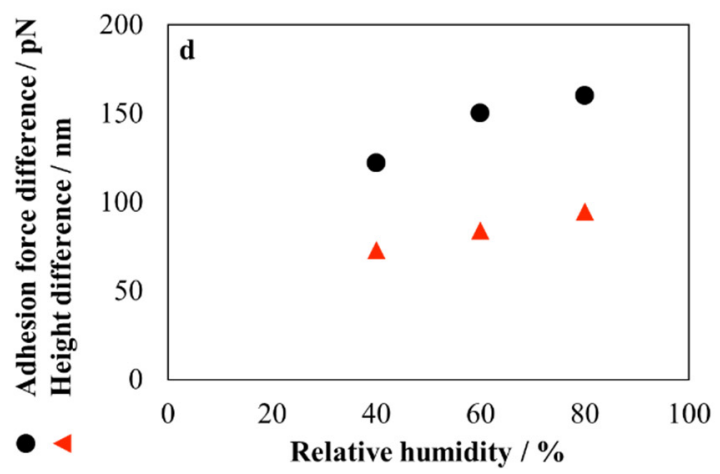

Figure 7. AFM adhesion mappings overlaid on 3D topography of the cross-sectioned interface of HMT-PMBI at (a) $40 \% \mathrm{RH}$, (b) $60 \% \mathrm{RH}$, (c) $80 \% \mathrm{RH}$, and (d) dependence of adhesion force and height of membrane above embedding material on 
RH.

The interface of the PPO-TMA membrane, on the other hand, showed a hydrophobic subsurface layer at the membrane-epoxy interface. A low-adhesive step at the interface, marked by a green arrow, can be seen in Figure 8(a) and (b). While the adhesion of the regular membrane surface increased with increasing $\mathrm{RH}$, adhesion of the subsurface layer did not, which means the hydrophobic subsurface layer stays intact even at high RH levels, and might hinder/slow down the WU of the membrane. Such difference of WU rate was confirmed by the kinetics study in the following section.

Comparison of the line-profiles of the very same area at $40 \%$ and $80 \% \mathrm{RH}$ (green and blue box in Figure 8) revealed that the membrane swelled by approximately $4 \mathrm{~nm}$ (Figure 8(c)). The increasing adhesion and swelling of the membrane suggest that within the time frame of the measurements $(<48 \mathrm{~h})$ at $\mathrm{RH}$ levels between $40 \%$ and $80 \% \mathrm{RH}$, no irreversible hydrophobic surface layer was built up. 


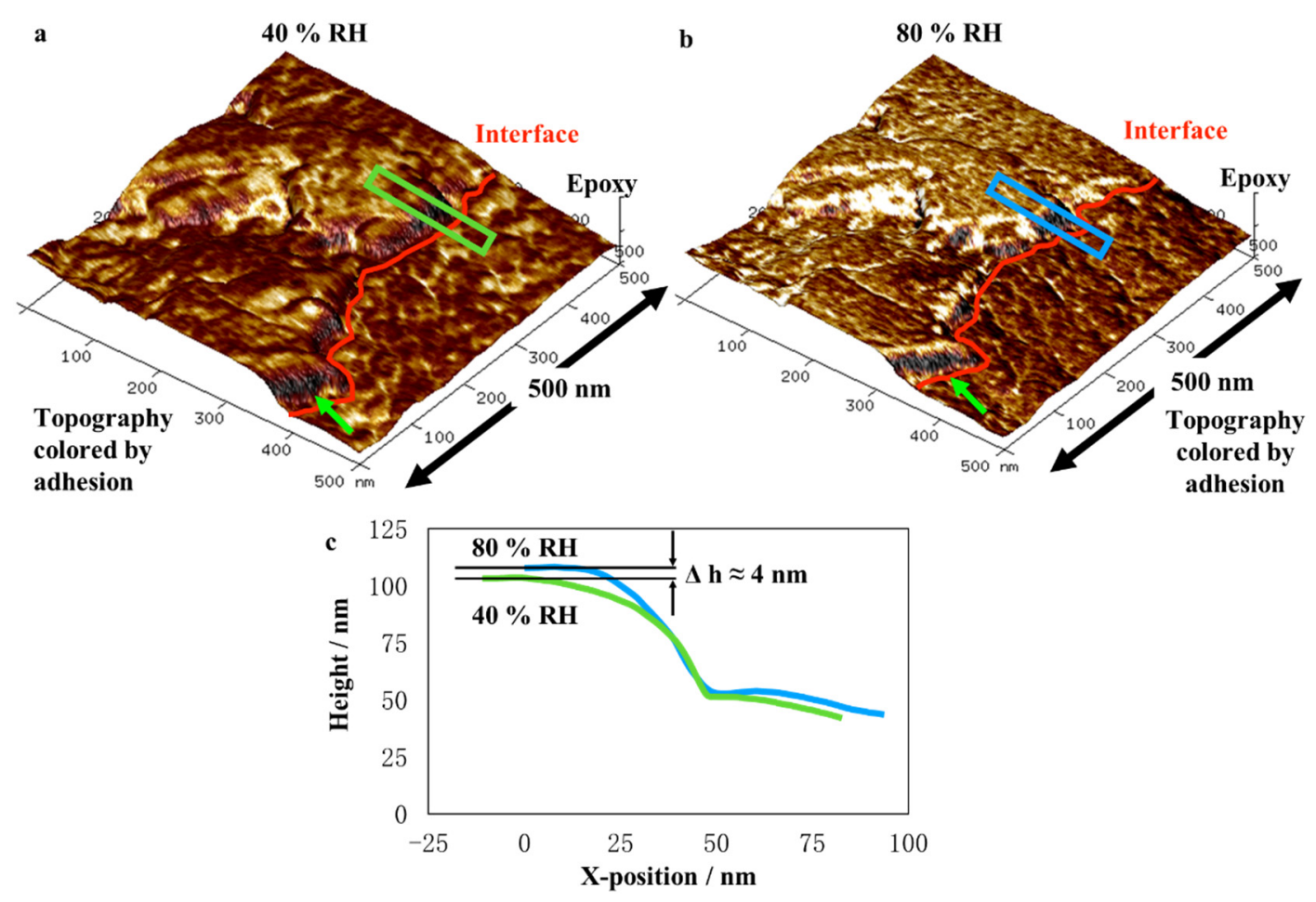

Figure 8. AFM adhesion mappings overlaid on topography of the cross-sectioned interface of PPO-TMA at (a) $40 \% \mathrm{RH}$, (b) $80 \% \mathrm{RH}$, and (c) the line profiles of height at different RH at the same spot marked by the green and blue box in (a) and (b), respectively.

WU kinetics from vapor. Since fuel cells are operated under dynamic conditions, fast WU responses to changes such as higher current demand is desirable for the AEMs. ${ }^{90}$ Fast rate of water transport across the cell AEM into the cathode is critical for high AEMFC performance and long-term chemical stability. ${ }^{62,63,91}$

Assuming all membranes show exponential kinetics, we derive the characteristic time constant, $\tau$, from the expression $\mathrm{M}_{t} / \mathrm{M}_{\infty}=1-\exp (-\mathrm{t} / \tau)$, as described in the experimental section. This time constant quantitatively evaluates the relative kinetic behavior of the different AEMs as a single parameter. 
Figure 9 summarizes the resulting $\tau$ for each of the RH steps through the entire RH range at $30{ }^{\circ} \mathrm{C}$. In this case, small $\mathrm{RH}$ increments were used $(5 \%-10 \%)$, in order to get a better resolution of the kinetic changes. Low $\tau$ values imply fast kinetic behavior, while high $\tau$ values signifies slow WU.

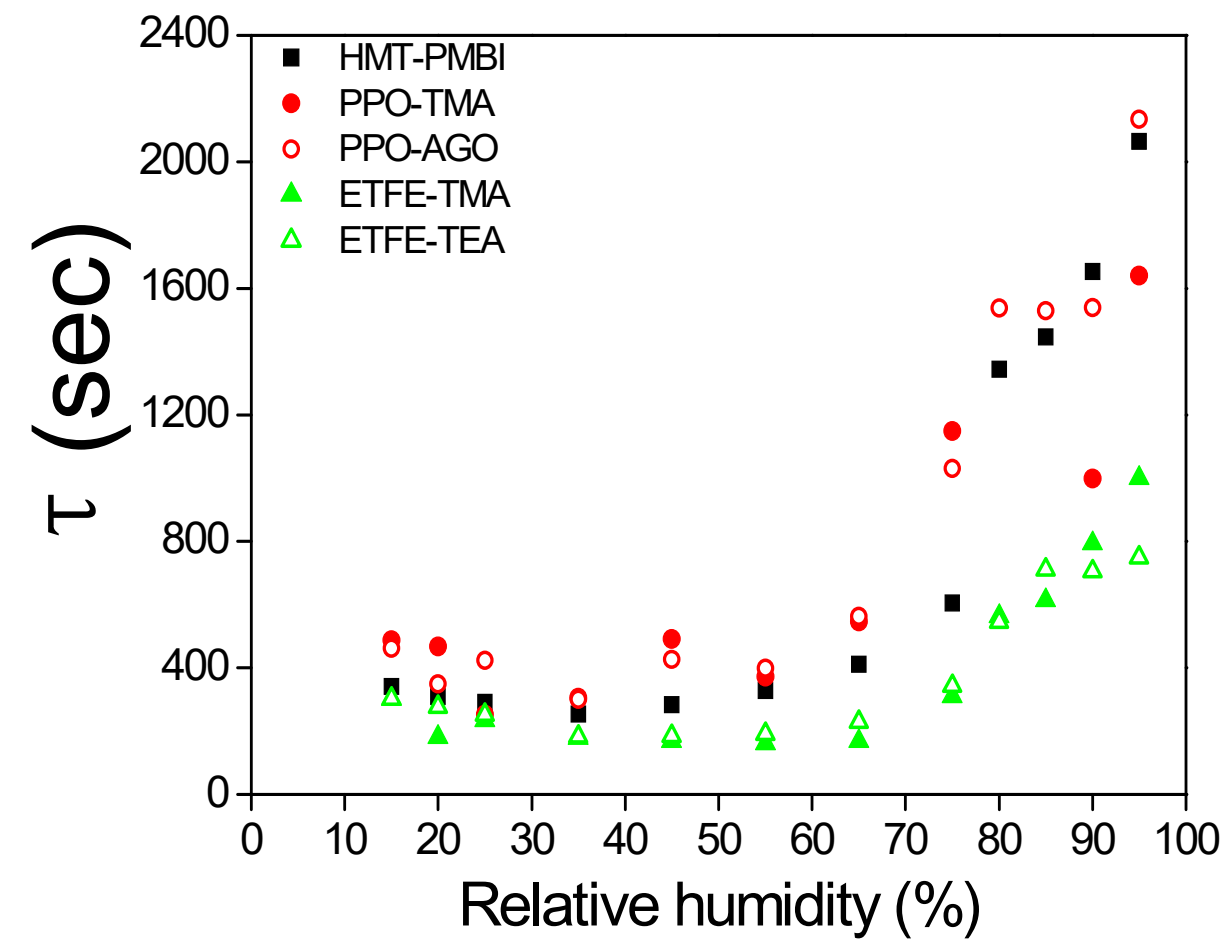

Figure 9. Characteristic time constant $\tau$, for HMT-PMBI, PPO-TMA, PPO-AGO, ETFE-TMA and ETFE-TEA membranes versus RH (15\%-95\%) at $30^{\circ} \mathrm{C}$.

All of the AEMs studied show a similar behavior of $\tau$ versus RH, with low $\tau(<500 \mathrm{~s})$ at low RHs, a slight decrease of $\tau$ towards a minimum at medium RHs, and a final sharp increase of $\tau(700-2000$ s) at RH $>70 \%$. ETFE membranes show the lowest $\tau$ throughout the entire $\mathrm{RH}$ range, probably due to the fast kinetics of water in the 
fluorinated structure of these membranes. Interestingly, all membranes present their lowest (and almost equal) $\tau$ at around $40 \% \mathrm{RH}$, meaning the fastest kinetics of these AEMs is at the mid-RH region. The higher $\tau$ (slower kinetics) at higher $\mathrm{RH}$ is typical for vapor WU kinetics. ${ }^{64}$ As mentioned in previous sections, the absorption mode at these RHs is clustering, where strong interactions between water molecules lead to a decrease in water mobility and consequently to a slower kinetics. ${ }^{92}$

Currently, AEMFCs operate at $60^{\circ} \mathrm{C}$, therefore we also studied the effect of temperature on the kinetics of water absorption in the AEMs. To simulate humidity conditions at the cathode catalyst layer of an AEMFC, we study the WU kinetics at low RH. Specifically, we used a modified experimental procedure and measured the WU transient response of the membrane to a sudden rise of $20 \%$ of the $\mathrm{RH}$, from $5 \%$ to $25 \% \mathrm{RH}$. To examine the effect of the RH level on the kinetics, we also measured the WU transient response at higher RH levels, from $25 \%$ to $45 \%$ and from $45 \%$ to $65 \%$. Figure 10 shows the individual WU transient response versus time of HMT-PMBI, PPO-TMA, PPO-AGO, ETFE-TMA and ETFE-TEAAEMs for each RH step-change (5\%-25\%, 25\%-45\%, and $45 \%-65 \%$ ) at both $30{ }^{\circ} \mathrm{C}$ and $60{ }^{\circ} \mathrm{C}$. For each $\mathrm{RH}$ step, the WU starts from zero, and we define the individual WU as:

$$
\text { Individual } \mathrm{WU}=\frac{W_{t}-W_{0}}{W_{d r y}} \times 100 \%
$$

where $\mathrm{W}_{\mathrm{t}}$ is the mass of sample at time $\mathrm{t}, \mathrm{W}_{0}$ is the mass at the beginning of the $\mathrm{RH}$ step, and $\mathrm{W}_{\text {dry }}$ is the mass of the dry membrane. 
For all membranes, the WU curves in Figure $\mathbf{1 0}$ go through a sharp increase immediately RH increase, followed by a slow, continuous rise until equilibrium after a few minutes. At $30{ }^{\circ} \mathrm{C}$, the WU kinetics seems to be $\mathrm{RH}$-independent. In contrast, at $60{ }^{\circ} \mathrm{C}$, as $\mathrm{RH}$ increases the dynamic WU becomes slower, and the time to reach WU equilibrium is longer. For example, WU in HMT-PMBI membrane reaches steady state at around $5 \mathrm{~min}$ at 5\%-25\% RH step, $7 \mathrm{~min}$ at $25 \%-45 \% \mathrm{RH}$ step, and more than 10 min at the $45 \%-65 \%$ RH step.

WU reaches equilibrium faster when the temperature increases from $30{ }^{\circ} \mathrm{C}$ to $60{ }^{\circ} \mathrm{C}$, especially at low RH (5\%-25\%, Figure 10(a), (d)). For each RH step, the positions of these curves with respect to each other in both temperatures are similar. HMT-PMBI has the fastest WU response and the highest WU at all RHs and temperatures studied. Therefore, an HMT-PMBI membrane uptake the same amount of water faster, as compared to all other AEMs. For instance, comparing the response of HMT-PMBI with that of PPO-AGO, which has the second-highest individual WU, HMT-PMBI reaches the equilibrium WU of PPO-AGO (4\%) about 6 times faster - after 5 min compared to 30 min (Figure 10(c)). 


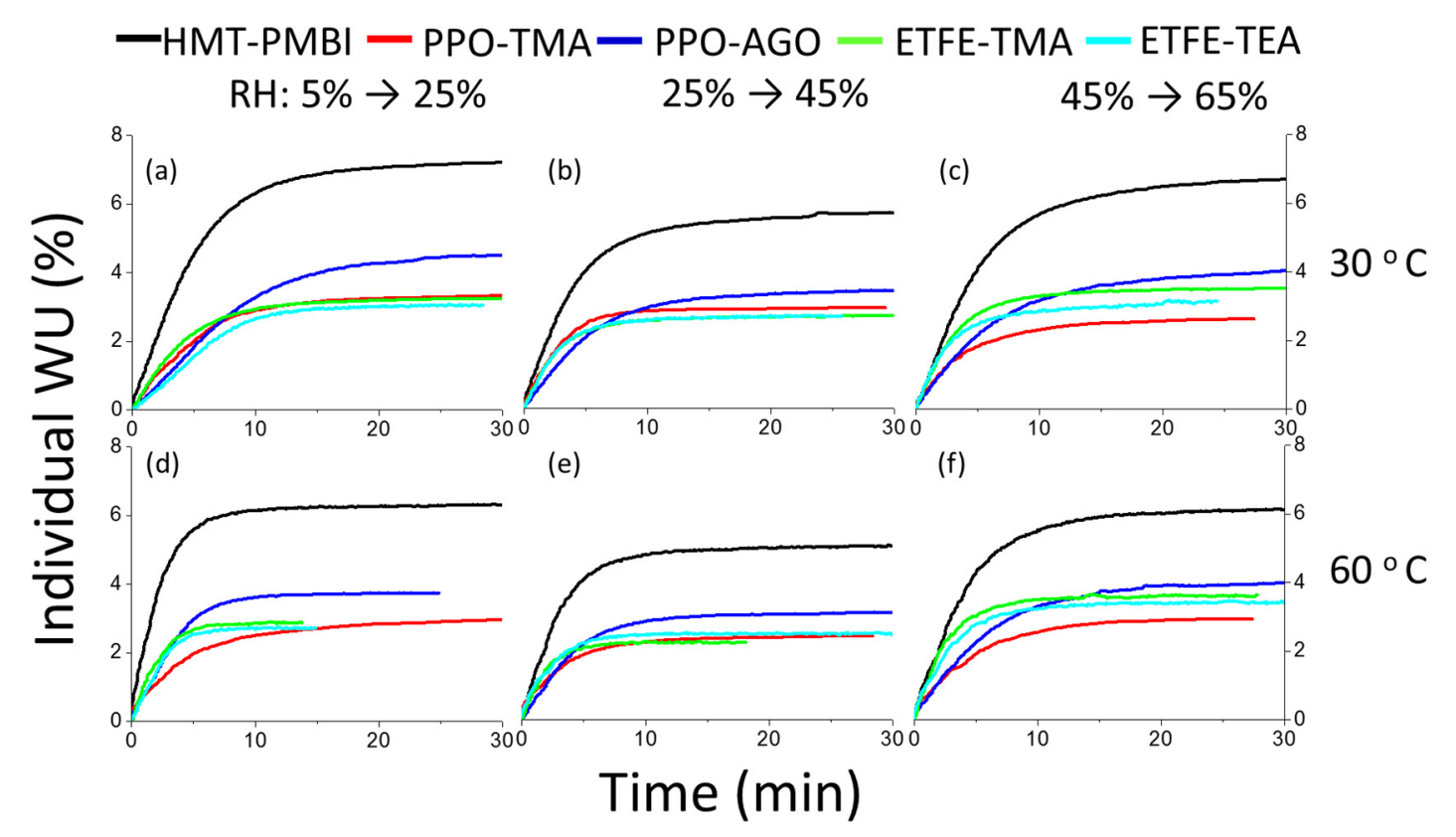

Figure 10. Individual WU of HMT-PMBI, PPO-TMA, PPO-AGO, ETFE-TMA and ETFE-TEA membranes versus time at three RH intervals: (a) and (d) 5\%-25\%; (b) and (e) $25 \%-45 \%$; (c) and (f) $45 \%-65 \%$ at $30{ }^{\circ} \mathrm{C}[(\mathrm{a})-(\mathrm{c})]$ and $60{ }^{\circ} \mathrm{C}[(\mathrm{d})-(\mathrm{f})]$.

Under all conditions shown in Figure 10, ETFE membranes similar kinetics in spite of their different FGs and different IECs. Though the final WU of ETFE is lower than PPO-AGO's (as already shown in Figure 10(a)), ETFE responds faster to an RH step it takes these membranes a shorter time (initially sharper slope) to equilibrate. This observation is clearer at high RH (Figure 10(c) and (f)). At $30^{\circ} \mathrm{C}$ and low-mid RH (Figure 10(a) and (b)), PPO-TMA takes up water faster than PPO-AGO; at $60{ }^{\circ} \mathrm{C}$ and low RH, PPO-AGO is faster (Figure 10(d)); in other conditions the PPO-based membranes behave similarly at short times, while PPO-AGO always has a higher final WU.

In order to get a better comparison of the WU kinetics, the WU dependence over time 
was normalized by the equilibrium (final) WU. In this way, the maximum normalized WU for all AEM is equal to one, making it is easier to compare the relative rate of each AEM. These normalized results, presented in Figure 11, highlight that while PPO-AGO has the slowest relative kinetics among all other studied AEMs, ETFE-based membranes have the fastest. The relative kinetics of absorption shows the following order ETFE-AEMs $>$ HMT-PMBI $>$ PPO. Following a similar analysis by Mangliali et al. ${ }^{72}$, we suggest that the faster ETFE-AEM kinetics is due to its polyolefin backbone, which may impart more flexible characteristics. ${ }^{72}$ However, this hypothesis should be further investigated in a more systematic variety of AEMs. Specifically, ETFE membranes at low RH levels (25\% to $45 \%)$ exhibit the fastest kinetics at both $30{ }^{\circ} \mathrm{C}$ and $60{ }^{\circ} \mathrm{C}$. ETFE-AEMs functionalized with both TMA and TEA have similar kinetics behavior, with the only exception at 5 to $25 \% \mathrm{RH}$ and $30{ }^{\circ} \mathrm{C}$, where ETFE-TMA exhibit faster WU response than ETFE-TEA. At a given RH step, temperature increase from $30{ }^{\circ} \mathrm{C}$ to $60{ }^{\circ} \mathrm{C}$ enhances WU kinetics for all membranes, as expected. This behavior was, for instance, previously described in PEM studies; ${ }^{93,94}$ however, never reported before for AEMs. The positive correlation of kinetics to temperature is more pronounced at low RH step. The normalized WU rate of HMT-PMBI approaches that of PPO-TMA as the RH increases, at both temperatures. 


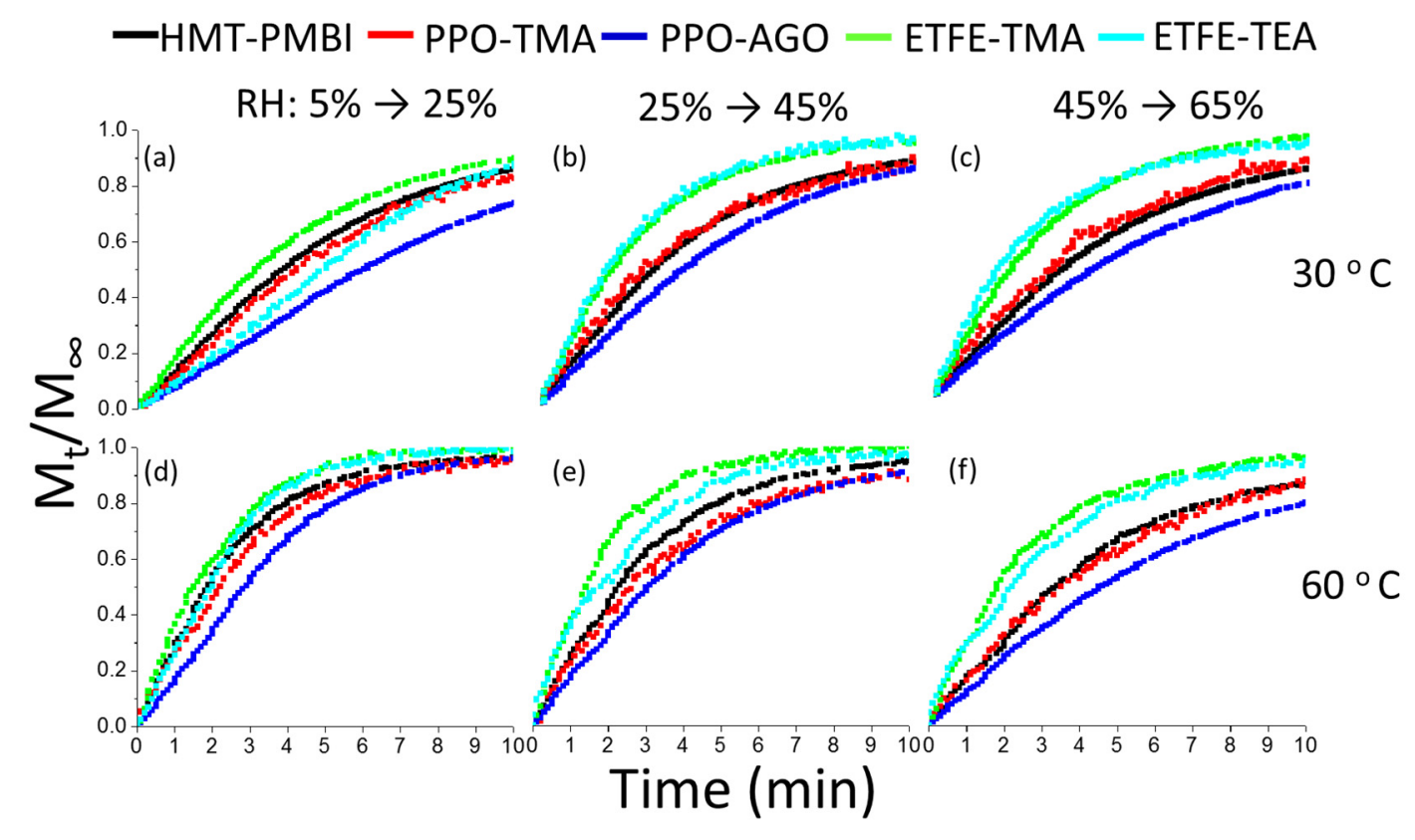

Figure 11. Normalized mass gain of HMT-PMBI, PPO-TMA, PPO-AGO, ETFE-

TMA and ETFE-TEA membranes versus time at three RH steps (5\%-25\%, 25\%-45\%, and $45 \%-65 \%)$ and two temperatures $\left(30^{\circ} \mathrm{C}\right.$ and $\left.60{ }^{\circ} \mathrm{C}\right)$.

Similarly to the discussion above, we used the characteristic time constant $\tau$ to analyze the effect of temperature on WU kinetics in the AEMs. Figure 12 shows $\tau$ for three different RH levels (in equal increment steps of 20\% RH), at different temperatures from $30^{\circ} \mathrm{C}$ to $60^{\circ} \mathrm{C}$, for HMT-PMBI and the ETFE-based AEMs. In general, for both AEMs the characteristic time constant $\tau$ decreases as temperature increases, as expected. As was previously observed, the $25 \%-45 \%$ medium $\mathrm{RH}$ range step exhibits the lowest $\tau$ and fastest kinetics. It is interesting to notice the different temperature dependence of the kinetics at different RH steps. At mid- and high-RH steps, $\tau$ shows a moderate decrease with initial increasing of temperature, and remains quite constant above $40{ }^{\circ} \mathrm{C}$. In contrast, at the $5 \%$ to $25 \%$ RH step (black dots), AEMs exhibit a clear decrease of $\tau$ 
from $30{ }^{\circ} \mathrm{C}$ to $60^{\circ} \mathrm{C}$. This difference will be further discussed in the following section.
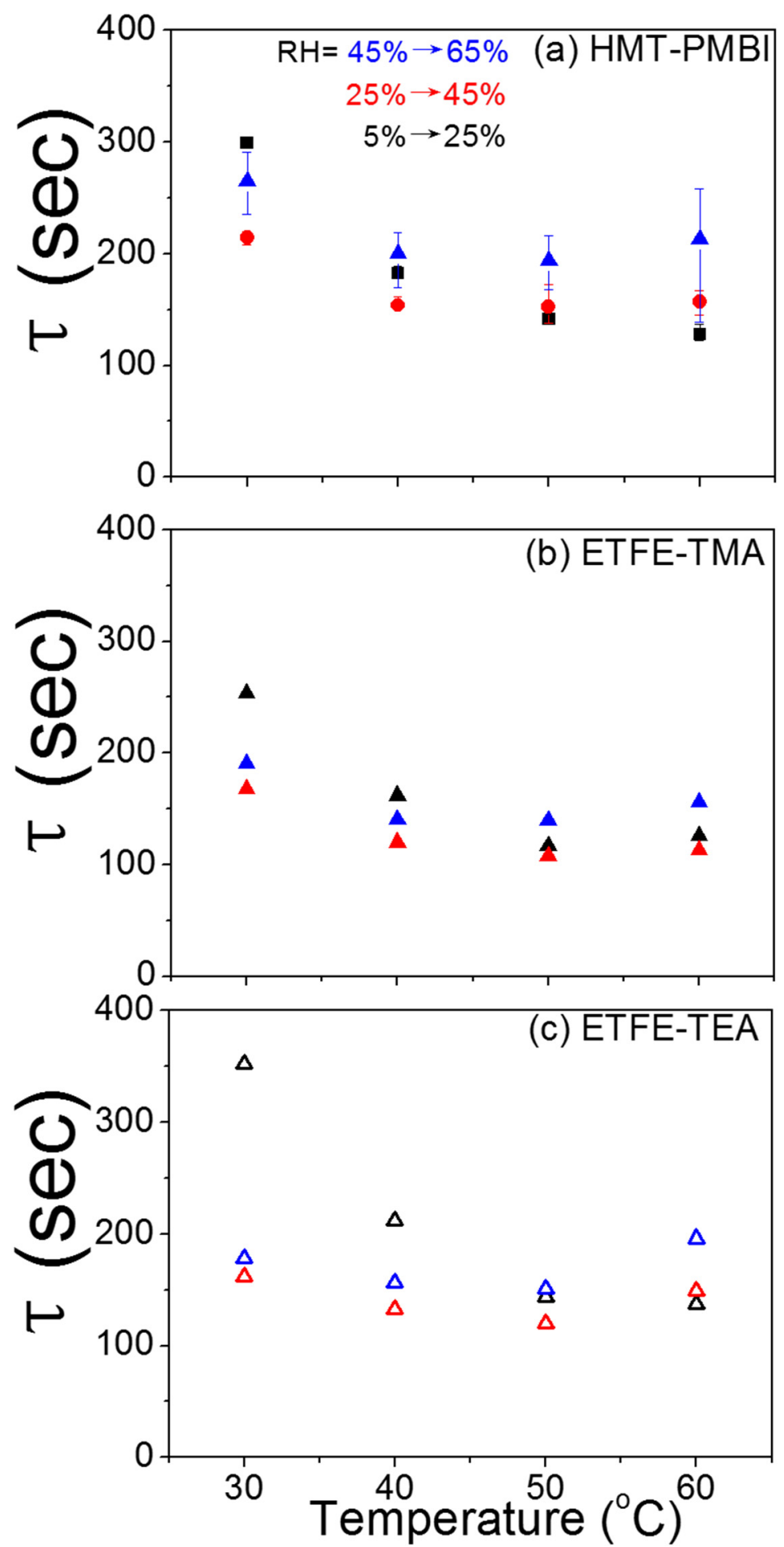

Figure 12. Characteristic time constant $\tau$ for (a) HMT-PMBI, (b) ETFE-TMA and (c) ETFE-TEA AEMs as a function of temperature. 
Water vapor absorption mechanism. In order to expand the understanding of AEM WU and WU kinetics, it is of interest to study the mechanism of water absorption. Vapor absorption kinetics may generally depend on three processes: (I) interfacial transport across the membrane/gas interface into the membrane; (II) diffusion through the membrane from the interface into the membrane; and (III) swelling of the membrane to accommodate water molecules inside. ${ }^{95,96}$

If the water absorption process is dominated by diffusion mechanism, the transport mechanism is said to be Fickian. ${ }^{95}$ If the water absorption process is dominated by mechanisms other than diffusion, or by a combination of different mechanisms, the process is called non-Fickian transport. For example, PEMs were commonly described by a non-Fickian transport mechanism, mainly attributed to the swelling of the membranes. ${ }^{97}$ The three transport mechanisms (I)-(III) roughly overlap the three absorption processes that govern equilibrium in the hydrated membranes: Langmuir (interface), Henry (diffusion) and clustering (relaxation/swelling). ${ }^{92}$ The WU kinetics we described above may be approximately described by these mechanisms. The WU kinetics in the $5 \%$ to $25 \% \mathrm{RH}$ step would be mostly based on interfacial (Langmuir) transport, with some diffusion (Henry) influence, following the boundaries of these models in our analysis (

Figure 4). Since temperature increase changes interfacial transport more than it changes diffusion, ${ }^{92}$ the enhancement of kinetics with increasing temperature at the $5 \%$ $25 \% \mathrm{RH}$ step is larger than at other RH ranges. This is consistent with the observation in Figure 12 of a sharp decrease of $\tau$ at $5 \%-25 \%$ RH, while a slight decrease was 
observed at other RH ranges. Similarly, the WU kinetics in the $25 \%$ to $45 \%$ RH step would be mostly based on diffusion (Henry) mechanism, which shows the fastest transport rate among the three mechanisms. ${ }^{98}$ This is also in line with the kinetics results presented in Figure 11 and Figure 12, where the mid-RH step showed the highest WU rate.

Other characteristics of non-Fickian mechanism are absorption and desorption curves that are non-linear and non-symmetric when plotted against square time, $\mathrm{t}^{1 / 2}$. For Fickian transport, on the other hand, absorption and desorption curves tend to be primarily linear and symmetric. ${ }^{94}$ In Figure 13, we compare the individual WU (absorption) and water loss (desorption) of HMT-PMBI, PPO-AGO and ETFE-TEA AEMs versus $\mathrm{t}^{1 / 2}$ at the three $\mathrm{RH}$ steps, at $60^{\circ} \mathrm{C}$. In general it can be seen that HMTPMBI and PPO-AGO membranes show similar behavior through all RH range. For both membranes, at the medium $\mathrm{RH}$ step, they present comparable absorption and desorption curves, suggesting a Fickian diffusion process. Similar RH-dependence of absorption mechanism was also previously reported for PEM ionomer membranes. ${ }^{99}$ At low and high RHs, the differences observed between absorption and desorption curves suggests a non-Fickian transport mechanism. The sigmoidal shape shown at low and high RHs was also previously reported by Rivin et al. ${ }^{100}$ and by Krtil ${ }^{101}$ in their studies on proton conducting Nafion membranes. This classic type of non-Fickican mechanism indicates that the transport mechanism is a combination of diffusion and interfacial mass transport processes. For HMT-PMBI and PPO-AGO, the absorption WU does not exceed desorption water loss at the low RH step (Figure 13 (a) and (d)). The contrary 
can be observed at the high RH step, where the absorption extent is larger than desorption one. Both phenomena are valid for all temperatures (see additional results in the Supporting Information). The diffusion-controlled transport at the $25 \%-45 \% \mathrm{RH}$ step is in line with the fast kinתetics of these membranes, since the diffusion coefficients of Fickian mechanism are generally higher than those of complex, non-Fickian processes. $^{102}$

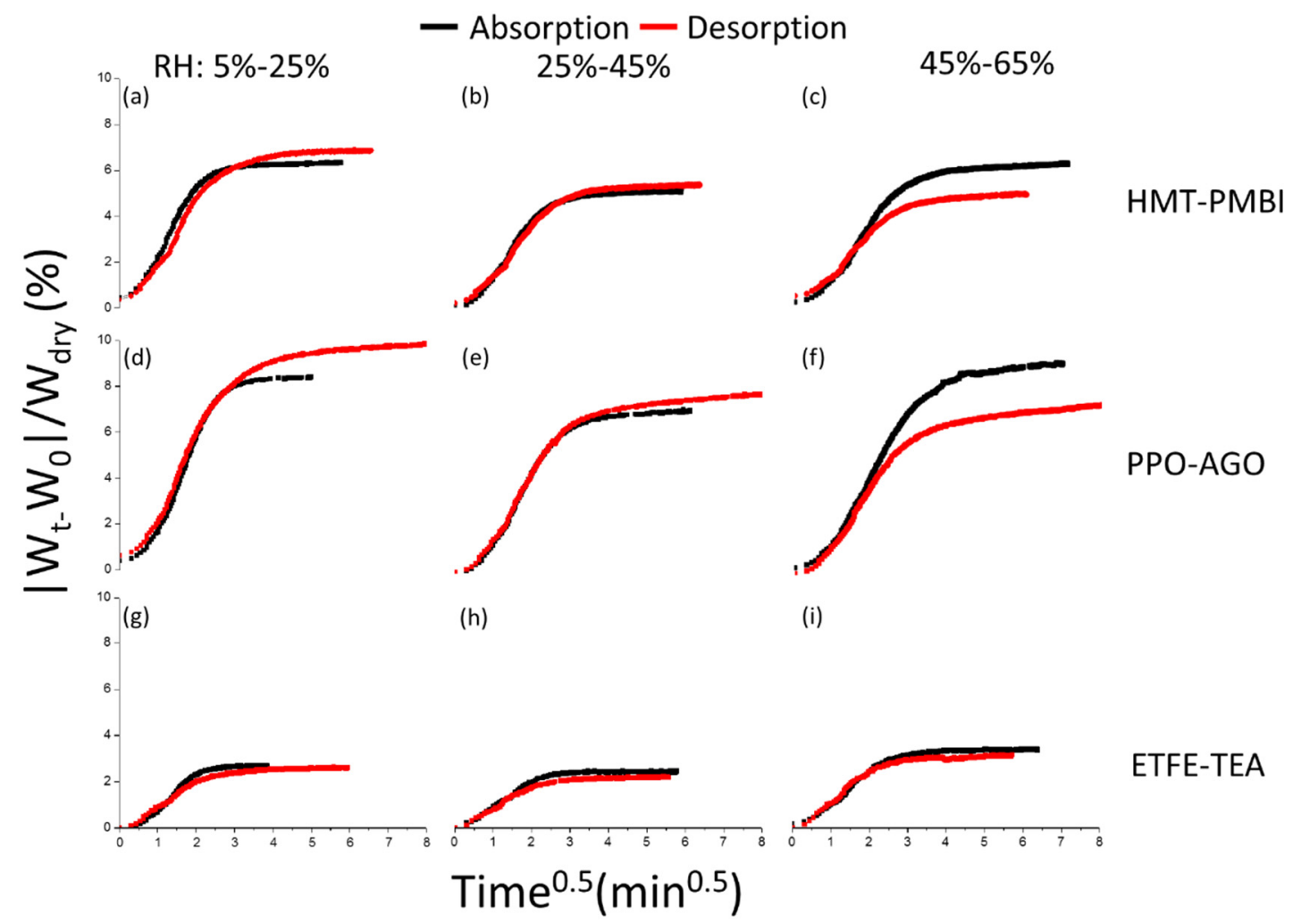

Figure 13. Absorption (black) and desorption (red) responses to RH increment steps, at $60{ }^{\circ} \mathrm{C}$ for different AEMs.

ETFE-TEA membranes on the other hand, show different results (Figure 13(g)-(i)). Non-sigmoidal, linear-like shape of the curves is observed at the beginning of the 
response. Also, the absorption and desorption curves are similar. The corresponding curves of ETFE-TMA (see Supporting Information) exhibit comparable behavior. Following the ideas mentioned above, this behavior suggests these membranes show characteristics of both non-Fickian and Fickian mechanism, which some studies called a pseudo-Fickian transport mechanism. ${ }^{103}$

Figure 13 supports our observations regarding some of the kinetic behaviors of the investigated membranes (Figure 11). The faster kinetics presented by the ETFE-based membranes in comparison to HMT-PMBI and PPO-based AEMs is associated with Fickian transport, as mentioned above. ${ }^{102}$ More information about the mechanism of water uptake in AEMs, especially at low RH levels, may be useful to overcome the drycathode phenomenon of AEMFCs at high current density. Further, systematic research with different AEMs is needed in order to understand the potential correlations of these observations to the desired AEM properties and in turn, to the final performance of AEMFCs. 


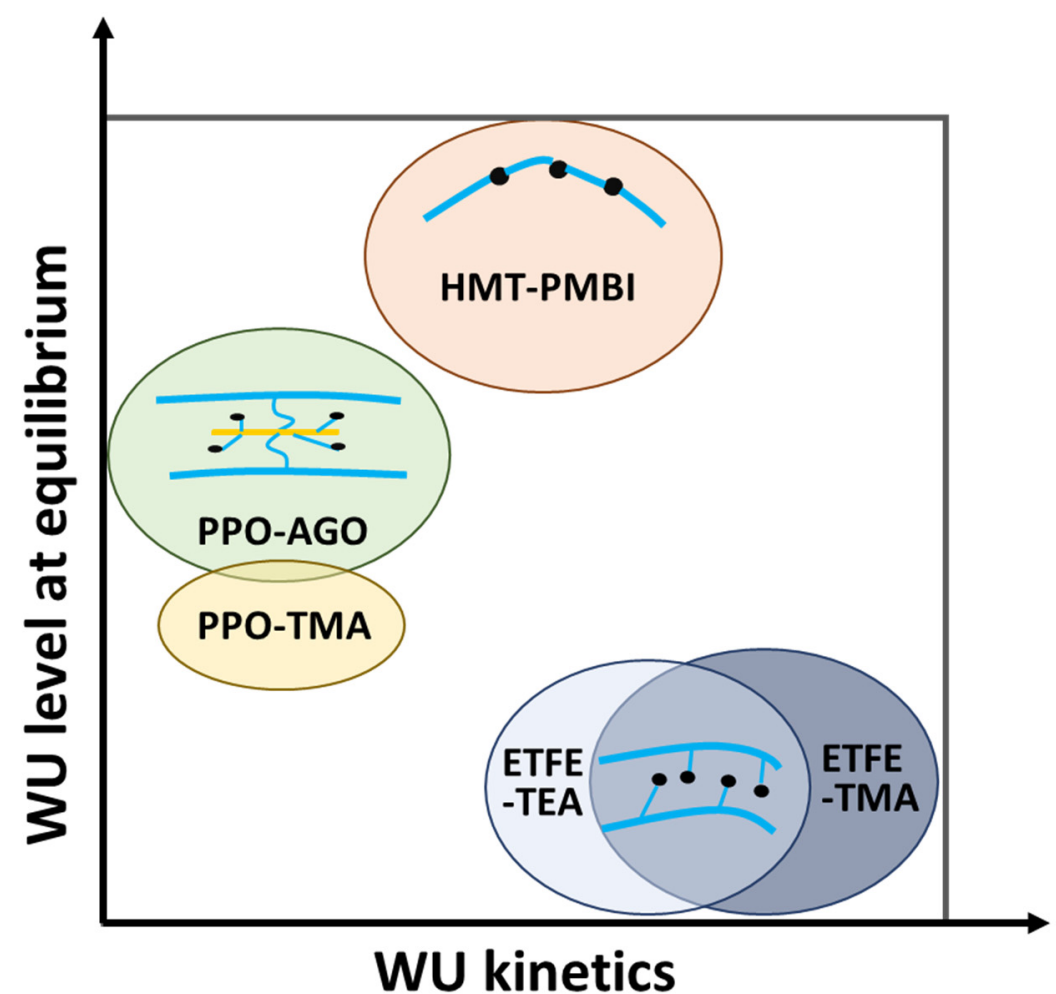

- Cationic group $\sim$ Polymer backbone Aminated graphene oxide

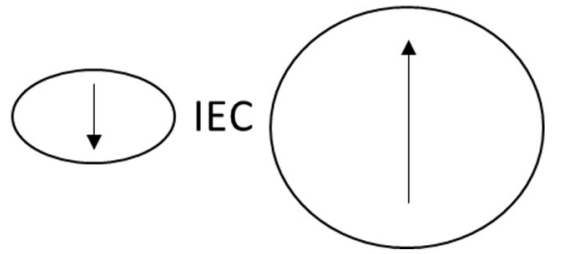

Figure 14. Schematic representation of WU and WU kinetics to map AEM WU properties.

Figure 14 schematically illustrates and summarizes the results observed on WU kinetics of the selected AEMs, while referring to their IECs, cationic groups and polymeric backbones. The ETFE-based membranes exhibit the fastest kinetics yet the lowest WU; HMT-PMBI membrane has the highest WU yet medium kinetics, while PPO-based membranes show the slowest kinetics with a medium level of WU. Based 
on previous research ${ }^{62,63,91}$, such WU properties may reflect on the potential use of a membrane in an AEMFC. More systematic studies in this front will allow a better characterization of AEMs.

\section{Conclusions}

Isothermal equilibrium water absorption measurements were performed on different AEMs based on HMT-PMBI, PPO, and radiation-grafted ETFE backbones. Detailed analyses of the water vapor isotherm modeling, successfully fitted by Park's model, were presented and discussed. HMT-PMBI has the highest equilibrium WU, while thecross-linked PPO-based AEM had a higher WU than the non-cross-linked PPO (despite a smaller water-to-FG ratio $\lambda$ ). The ETFE-based AEMs exhibited the lowest WUs and hydration numbers compared to all the other AEMs tested. The kinetics of WU was also measured and discussed. In general, WU kinetics follow the order ETFE- > HMT-PMBI- > PPO- based AEMs. AFM measurements support this observation: as stable hydrophobic subsurface layer was formed in PPO-TMA membrane, the WU kinetics slows down, while HMT-PMBI has no detectable hydrophobic interface.

The results obtained in this work indicate that the WU kinetics is significantly affected by temperature and $\mathrm{RH}$. With an increase of temperature, the kinetics were observed to be faster. The influence of $\mathrm{RH}$ on kinetics was explained by a combination of diffusion, interfacial transport and swelling processes. At low $\mathrm{RH}$, water absorption was dominated by an interfacial transport mechanism. At mid-RH levels, the process was 
dominated by diffusion and the AEMs exhibited the fastest WU kinetics. At high RH, the water molecules began to aggregate and form clusters, which blocked the water transport pathway and hinder WU kinetics.

A characteristic time constant $\tau$ was used to quantify the kinetics of different AEMsat over a range of $\mathrm{RH}$ levels and temperatures. Finally, possible mechanisms of water transport through the AEMs were analyzed. All the studied AEMs showed Fickian behavior at moderate $\mathrm{RH}$ step changes $(25 \% \rightarrow 45 \%)$. Non-Fickian absorption was observed in HMT-PMBI and PPO-based membranes over both low $(5 \% \rightarrow 25 \%)$ and high $(45 \% \rightarrow 65 \%)$ RH step changes. Pseudo-Fickian behavior through the whole RH range was observed with the ETFE-based AEMs, which shows the fastest WU kinetics among all studied AEMs.

This work provides first insights into a promising method for characterizing AEMs vy quantifying both the equilibrium WUs and kinetics of WU. To the best of our knowledge, this is the first study of WU kinetics related to AEMs. Wider, systematic WU kinetic data on a broader range of AEMs is now required to provide critical information for the design of next-generation AEM-based fuel cells with improved water management characteristics. Moreover, a combination of individual WU and normalized WU versus time, as presented in this study, provides two different eharacteristics of the material. Such systematic data on other types of common AEMs ean allow useful insights into design of anion conducting ionomers and membranes to be used in high-performance AEMFCs in the future. 


\section{Nomenclature}

Acronyms:

WU - water uptake

AEM - anion exchange membrane

PPO - poly(phenylene oxide)

PPO-TMA - poly(phenylene oxide) membranes functionalized with trimethylamine

PPO-AGO - poly(phenylene oxide) crosslinked with aminated graphene oxide

HMT-PMBI - 2,2",4,4",6,6"-hexamethyl-p-terphenylene-b-N-methylated

poly(benzimidazolium)s membrane

ETFE-TMA - poly(ethylene-co-tetrafluoroethylene)-g-polyvinylbenzyl membrane

functionalised with trimethylamine

ETFE-TEA - poly(ethylene-co-tetrafluoroethylene)-g-polyvinylbenzyl membrane

functionalised with triethylamine

$\mathrm{RH}$ - relative humidity

AEMFCs - anion-exchange membrane fuel cells

PEMFCs - proton-exchange membrane fuel cells

PEM - proton-exchange membrane

QA - quaternary ammonium groups

FG - functional groups

IEC - ion exchange capacity

AFM - atomic force microscopy 
SER - Sentmanat Extension Rheometer

FCO - Forced Convection Oven

NDMS - New Dual Mode Sorption

\section{Acknowledgements}

This work was partially funded by the Grand Technion Energy Program (GTEP); by the European Union's Horizon 2020 research and innovation program [grant no. 721065]; by the Ministry of Science, Technology \& Space of Israel through the M.eraNET Transnational Call 2015, NEXTGAME project [grant no. 3-12948]; by the 2nd Israel National Research Center for Electrochemical Propulsion (INREP2-ISF); by the Ministry of Energy of Israel [grant no. 3-13671]. Mechanical property measurements were partially supported by the U.S. Army Research Office (MURI Grant W911NF10-1-0520 and DURIP Grant W911NF-11-1-0306). One of the authors (Y.Z.) would like to thank the kind partial financial support from the Lady Davis Fellowship Trust. The ETFE-based AEMs were prepared using funding provided by the UK's Engineering and Physical Sciences Research Council (EPSRC grant EP/M005933/1).

\section{Supporting Information}

Synthesis of graphite oxide (GO)

Synthesis of DMAPSiGO [(N,N-Dimethylaminopropyl)silane graphene oxide]

Synthesis of imidazolium-functionalized (N,N Dimethylaminopropyl)silane graphene oxide (aminated graphene oxide, AGO) cross-linker

Preparation of brominated poly(phenylene oxide) (Br-PPO)

Preparation of PPO-TMA membrane

Preparation of PPO-AGO membrane 
AFM measurement

WU equilibrium

AFM characterization

WU kinetics from vapor

Water vapor absorption mechanism

\section{References:}

(1) Varcoe, J. R.; Atanassov, P.; Dekel, D. R.; Herring, A. M.; Hickner, M. A.; Kohl, P. A.; Kucernak, A. R.; Mustain, W. E.; Nijmeijer, K.; Scott, K.; Xu, T.; Zhuang, L. Anion-Exchange Membranes in Electrochemical Energy Systems. Energy Environ. Sci. 2014, 7, 3135-3191 DOI: 10.1039/b000000x.

(2) Dekel, D. R. Alkaline Membrane Fuel Cells, Membranes. In Encyclopedia of Applied Electrochemistry; 2014; pp 33-45.

(3) Merle, G.; Wessling, M.; Nijmeijer, K. Anion Exchange Membranes for Alkaline Fuel Cells: A Review. J. Memb. Sci. 2011, 377 (1-2), 1-35 DOI: 10.1016/j.memsci.2011.04.043.

(4) Dekel, D. Alkaline Membrane Fuel Cells. In Encyclopedia of Applied Electrochemistry; Kreysa, G., Ota, K., Savinell, R. F., Eds.; Springer New York: New York, NY, 2014; pp 26-33.

(5) Stoica, D.; Alloin, F.; Marais, S.; Langevin, D.; Chappey, C.; Judeinstein, P. Polyepichlorohydrin Membranes for Alkaline Fuel Cells: Sorption and Conduction Properties. J. Phys. Chem. B 2008, 112 (39), 12338-12346 DOI: 10.1021/jp804787x. 
(6) Duan, Q.; Ge, S.; Wang, C. Y. Water Uptake, Ionic Conductivity and Swelling Properties of Anion-Exchange Membrane. J. Power Sources 2013, 243, 773778 DOI: 10.1016/j.jpowsour.2013.06.095.

(7) Bharath, V. J.; Millichamp, J.; Neville, T. P.; Mason, T.; Shearing, P. R.; Brown, R. J. .; Manos, G.; Brett, D. J. L. Measurement of Water Uptake in Thin-Film Nafion and Anion Alkaline Exchange Membranes Using the Quartz Crystal Microbalance. J. Memb. Sci. 2015, 497, 229-238 DOI:

10.1016/j.memsci.2015.09.027.

(8) Li, Y. S.; Zhao, T. S.; Yang, W. W. Measurements of Water Uptake and Transport Properties in Anion-Exchange Membranes. Int. J. Hydrogen Energy 2010, 35 (11), 5656-5665 DOI: 10.1016/j.ijhydene.2010.03.026.

(9) Liu, Y.; Wang, J.; Yang, Y.; Brenner, T. M.; Seifert, S.; Yan, Y.; Liberatore, M. W.; Herring, A. M. Anion Transport in a Chemically Stable, Sterically Bulky $\alpha-C$ Modified Imidazolium Functionalized Anion Exchange Membrane. J. Phys. Chem. C 2014, 118 (28), 15136-15145 DOI: 10.1021/jp5027674.

(10) Ye, Y.; Stokes, K. K.; Beyer, F. L.; Elabd, Y. A. Development of Phosphonium-Based Bicarbonate Anion Exchange Polymer Membranes. $J$. Memb. Sci. 2013, 443, 93-99 DOI: 10.1016/j.memsci.2013.04.053.

(11) Varcoe, J. R. Investigations of the Ex Situ Ionic Conductivities at $30^{\circ} \mathrm{C}$ of Metal-Cation-Free Quaternary Ammonium Alkaline Anion-Exchange Membranes in Static Atmospheres of Different Relative Humidities. Phys. Chem. Chem. Phys. 2007, 9 (12), 1479-1486 DOI: 10.1039/b615478f. 
(12) Ran, J.; Wu, L.; Ge, Q.; Chen, Y.; Xu, T. High Performance Anion Exchange Membranes Obtained through Graft Architecture and Rational Cross-Linking. J. Memb. Sci. 2014, 470, 229-236 DOI: 10.1016/j.memsci.2014.07.036.

(13) Li, X.; Liu, Q.; Yu, Y.; Meng, Y. Synthesis and Properties of Multiblock Ionomers Containing Densely Functionalized Hydrophilic Blocks for Anion Exchange Membranes. J. Memb. Sci. 2014, 467, 1-12 DOI: 10.1016/j.memsci.2014.05.016.

(14) Espiritu, R.; Mamlouk, M.; Scott, K. Study on the Effect of the Degree of Grafting on the Performance of Polyethylene-Based Anion Exchange Membrane for Fuel Cell Application. Int. J. Hydrogen Energy 2016, 41 (2), 1120-1133 DOI: 10.1016/j.ijhydene.2015.10.108.

(15) Hossain, M. A.; Lim, Y.; Lee, S.; Jang, H.; Choi, S.; Jeon, Y.; Lim, J.; Kim, W. G. Comparison of Alkaline Fuel Cell Membranes of Random \& Block Poly(arylene Ether Sulfone) Copolymers Containing Tetra Quaternary Ammonium Hydroxides. Int. J. Hydrogen Energy 2014, 39 (6), 2731-2739 DOI: 10.1016/j.ijhydene.2013.01.197.

(16) Lee, H.-C.; Liu, K.-L.; Tsai, L.-D.; Lai, J.-Y.; Chao, C.-Y. Anion Exchange Membranes Based on Novel Quaternized Block Copolymers for Alkaline Direct Methanol Fuel Cells. RSC Adv. 2014, 4 (21), 10944 DOI: 10.1039/c3ra47886f.

(17) Li, Q.; Liu, L.; Miao, Q.; Jin, B.; Bai, R. Hydroxide-Conducting Polymer Electrolyte Membranes from Aromatic ABA Triblock Copolymers. Polym. 
Chem. 2014, 5 (7), 2208-2213 DOI: 10.1039/C3PY01673K.

(18) Li, X.; Nie, G.; Tao, J.; Wu, W.; Wang, L.; Liao, S. Assessing the Influence of Side-Chain and Main-Chain Aromatic Benzyltrimethyl Ammonium on Anion Exchange Membranes. ACS Appl. Mater. Interfaces 2014, 6 (10), 7585-7595 DOI: $10.1021 / \mathrm{am} 500915 \mathrm{w}$.

(19) Song, F.; Fu, Y.; Gao, Y.; Li, J.; Qiao, J.; Zhou, X. D.; Liu, Y. Novel Alkaline Anion-Exchange Membranes Based on

Chitosan/Ethenylmethylimidazoliumchloride Polymer with Ethenylpyrrolidone Composites for Low Temperature Polymer Electrolyte Fuel Cells. Electrochim. Acta 2015, 177, 137-144 DOI: 10.1016/j.electacta.2015.02.015.

(20) Wang, G.; Weng, Y.; Chu, D.; Xie, D.; Chen, R. Preparation of Alkaline Anion Exchange Membranes Based on Functional Poly(ether-Imide) Polymers for Potential Fuel Cell Applications. J. Memb. Sci. 2009, 326 (1), 4-8 DOI: 10.1016/j.memsci.2008.09.037.

(21) Wang, J.; Li, S.; Zhang, S. Novel Hydroxide-Conducting Polyelectrolyte Composed of an Poly(arylene Ether Sulfone) Containing Pendant Quaternary Guanidinium Groups for Alkaline Fuel Cell Applications. Macromolecules 2010, 43 (8), 3890-3896 DOI: 10.1021/ma100260a.

(22) Sajjad, S. D.; Hong, Y.; Liu, F. Synthesis of Guanidinium-Based Anion Exchange Membranes and Their Stability Assessment. Polym. Adv. Technol. 2014, 25 (1), 108-116 DOI: 10.1002/pat.3211.

(23) Singh, A. K.; Pandey, R. P.; Shahi, V. K. Fluorenyl Phenolphthalein Groups 
Containing a Multi-Block Copolymer Membrane for Alkaline Fuel Cells. RSC $A d v$. 2014, 4 (42), 22186 DOI: 10.1039/c4ra01999g.

(24) Mohanty, A. D.; Lee, Y.-B.; Zhu, L.; Hickner, M. a.; Bae, C. Anion Exchange Fuel Cell Membranes Prepared from C-H Borylation and Suzuki Coupling Reactions. Macromolecules 2014, 47 (6), 1973-1980 DOI:

$10.1021 / \mathrm{ma} 500125 \mathrm{t}$.

(25) Yu Xu, P.; Zhou, K.; Lu Han, G.; Gen Zhang, Q.; Mei Zhu, A.; Lin Liu, Q. Fluorene-Containing Poly(arylene Ether Sulfone)s as Anion Exchange Membranes for Alkaline Fuel Cells. J. Memb. Sci. 2014, 457, 29-38 DOI: 10.1016/j.memsci.2014.01.042.

(26) Lin, X.; Wu, L.; Liu, Y.; Ong, A. L.; Poynton, S. D.; Varcoe, J. R.; Xu, T. Alkali Resistant and Conductive Guanidinium-Based Anion-Exchange Membranes for Alkaline Polymer Electrolyte Fuel Cells. J. Power Sources 2012, 217, 373-380 DOI: 10.1016/j.jpowsour.2012.05.062.

(27) Wang, C.; Xu, C.; Shen, B.; Zhao, X.; Li, J. Stable Poly(arylene Ether Sulfone)s Anion Exchange Membranes Containing Imidazolium Cations on Pendant Phenyl Rings. Electrochim. Acta 2016, 190, 1057-1065 DOI: 10.1016/j.electacta.2015.12.181.

(28) Lai, A. N.; Zhuo, Y. Z.; Lin, C. X.; Zhang, Q. G.; Zhu, A. M.; Ye, M. L.; Liu, Q. L. Side-Chain-Type Phenolphthalein-Based Poly(arylene Ether Sulfone Nitrile)s Anion Exchange Membrane for Fuel Cells. J. Memb. Sci. 2016, 502, 94-105 DOI: 10.1016/j.memsci.2015.12.044. 
(29) Hossain, M. A.; Lim, Y.; Lee, S.; Jang, H.; Choi, S.; Jeon, Y.; Lee, S.; Ju, H.; Kim, W. G. Anion Conductive Aromatic Membrane of Poly(tetra Phenyl Ether Sulfone) Containing Hexa-Imidazolium Hydroxides for Alkaline Fuel Cell Application. Solid State Ionics 2014, 262, 754-760 DOI:

10.1016/j.ssi.2013.09.036.

(30) Gao, Y.; Song, F.; Qiao, J.; Chen, S.; Zhao, X.; Zhang, J. ImidazoliumFunctionalized Anion Exchange Polymer Electrolytes with High Tensile Strength and Stability for Alkaline Membrane Fuel Cells. Electrochim. Acta 2015, 177, 201-208 DOI: 10.1016/j.electacta.2015.01.164.

(31) Li, C.; Wang, S.; Wang, W.; Xie, X.; Lv, Y.; Deng, C. A Cross-Linked Fluorinated Poly (Aryl Ether Oxadiazole) S Using a Thermal Cross-Linking for Anion Exchange Membranes. Int. J. Hydrogen Energy 2013, 38 (25), 11038 11044 DOI: 10.1016/j.ijhydene.2013.03.172.

(32) Lee, M.-S.; Kim, T.; Park, S.-H.; Kim, C.-S.; Choi, Y.-W. A Highly Durable Cross-Linked Hydroxide Ion Conducting Pore-Filling Membrane. J. Mater.

Chem. 2012, 22 (28), 13928-13931 DOI: 10.1039/c2jm32628k.

(33) Disabb-Miller, M. L.; Zha, Y.; DeCarlo, A. J.; Pawar, M.; Tew, G. N.; Hickner, M. a. Water Uptake and Ion Mobility in Cross-Linked Bis(terpyridine)ruthenium-Based Anion Exchange Membranes. Macromolecules 2013, 46 (23), 9279-9287 DOI: 10.1021/ma401701n.

(34) Yang, Y.; Wang, J.; Zheng, J.; Li, S.; Zhang, S. A Stable Anion Exchange Membrane Based on Imidazolium Salt for Alkaline Fuel Cell. J. Memb. Sci. 
2014, 467, 48-55 DOI: 10.1016/j.memsci.2014.05.017.

(35) Liu, M.; Wang, Z.; Mei, J.; Xu, J.; Xu, L.; Han, H.; Ni, H.; Wang, S. A Facile Functionalized Routine for the Synthesis of Imidazolium-Based AnionExchange Membrane with Excellent Alkaline Stability. J. Memb. Sci. 2016, 505, 138-147 DOI: 10.1016/j.memsci.2016.01.036.

(36) He, Y.; Wu, L.; Pan, J.; Zhu, Y.; Ge, X.; Yang, Z.; Ran, J.; Xu, T. A Mechanically Robust Anion Exchange Membrane with High Hydroxide Conductivity. J. Memb. Sci. 2016, 504, 47-54 DOI:

10.1016/j.memsci.2016.01.008.

(37) Amel, A.; Smedley, S. B.; Dekel, D. R.; Hickner, M. A.; Ein-Eli, Y. Characterization and Chemical Stability of Anion Exchange Membranes CrossLinked with Polar Electron-Donating Linkers. J. Electrochem. Soc. 2015, 162 (9), F1047-F1055 DOI: 10.1149/2.0891509jes.

(38) Lu, W.; Shao, Z. G.; Zhang, G.; Zhao, Y.; Yi, B. Crosslinked Poly(vinylbenzyl Chloride) with a Macromolecular Crosslinker for Anion Exchange Membrane Fuel Cells. J. Power Sources 2014, 248, 905-914 DOI:

10.1016/j.jpowsour.2013.08.141.

(39) Li, X.; Tao, J.; Nie, G.; Wang, L.; Li, L.; Liao, S. Cross-Linked Multiblock Copoly(arylene Ether Sulfone) Ionomer/nano-ZrO 2 Composite Anion Exchange Membranes for Alkaline Fuel Cells. RSC Adv. 2014, 4 (78), 4139841410 DOI: 10.1039/C4RA06519K.

(40) Zhou, J.; Ünlü, M.; Anestis-Richard, I.; Kohl, P. A. Crosslinked, Epoxy-Based 
Anion Conductive Membranes for Alkaline Membrane Fuel Cells. J. Memb.

Sci. 2010, 350 (1-2), 286-292 DOI: 10.1016/j.memsci.2010.01.003.

(41) Amel, A.; Zhu, L.; Hickner, M.; Ein-Eli, Y. Influence of Sulfone Linkage on the Stability of Aromatic Quaternary Ammonium Polymers for Alkaline Fuel Cells. J. Electrochem. Soc. 2014, 161 (5), F615-F621 DOI:

$10.1149 / 2.044405 j$ jes.

(42) Janarthanan, R.; Horan, J. L.; Caire, B. R.; Ziegler, Z. C.; Yang, Y.; Zuo, X.; Liberatore, M. W.; Hibbs, M. R.; Herring, A. M. Understanding Anion Transport in an Aminated Trimethyl Polyphenylene with High Anionic Conductivity. J. Polym. Sci. Part B Polym. Phys. 2013, 51 (24), 1743-1750 DOI: $10.1002 /$ polb.23164.

(43) Tsonos, C.; Apekis, L.; Pissis, P. Water Sorption and Dielectric Relaxation Spectroscopy Studies in Hydrated Nafion ${ }^{\circledR}$ ( -SO 3 K ) Membranes. J. Mater. Sci. 2000, 35, 5957-5965.

(44) Perrin, J. C.; Lyonnard, S.; Guillermo, A.; Levitz, P. Water Dynamics in Lonomer Membranes by Field-Cycling NMR Relaxometry. Fuel cells 2006, 6 (1), 5-9 DOI: 10.1021/jp057433e.

(45) Grew, K. N.; Chiu, W. K. S. A Dusty Fluid Model for Predicting Hydroxyl Anion Conductivity in Alkaline Anion Exchange Membranes. 2010 DOI: 10.1149/1.3273200.

(46) Kim, Y. S.; Pivovar, B. S. Moving Beyond Mass-Based Parameters for Conductivity Analysis of Sulfonated Polymers. Annu. Rev. Chem. Biomol. Eng. 
2010, 1 (1), 123-148 DOI: 10.1146/annurev-chembioeng-073009-101309.

(47) Rosa, F.; Bordado, J.; Casquilho, M. Kinetics of Water Absorbency in AA/AMPS Copolymers: Applications of a Diffusion-Relaxation Model.

Polymer (Guildf). 2001, 43 (1), 63-70 DOI: 10.1016/S0032-3861(01)00596-1.

(48) Berens, A. R.; Hopfenberg, H. B. Diffusion and Relaxation in Glassy Polymer Powders: 2. Separation of Diffusion and Relaxation Parameters. Polymer (Guildf). 1978, 19 (5), 489-496 DOI: 10.1016/0032-3861(78)90269-0.

(49) Jacobs, P. M.; Jones, E. R. Diffusion of Moisture into Two-Phase Polymers Part 1 The Development of an Analytical Mode/and Its Application to StyreneEthylene/butylene-Styrene Block Copolymer. J. Mater. Sci. 1989, 24 (7), 2331-2336 DOI: 10.1007/BF01174494.

(50) Jacobs, P. M.; Jones, E. R. Diffusion of Moisture into Two-Phase Polymers Part 2 Styrenated Polyester Resins. J. Mater. Sci. 1989, 24 (7), 2343-2348 DOI: $10.1007 / \mathrm{BF} 01174494$.

(51) MAGGANA, C.; PISSIS, P. Water Sorption and Diffusion in an Epoxy Resin System. J. Polym. Sci. Part B-Polymer Phys. 1999, 37, 1165-1182 DOI: 10.1002/(SICI)1099-0488(19990601)37:11<1165::AID-POLB11>3.0.CO;2-E.

(52) Moilanen, D. E.; Piletic, I. R.; Fayer, M. D. Water Dynamics in Nafion Fuel Cell Membranes: The Effects of Confinement and Structural Changes on the Hydrogen Bond Network. J. Phys. Chem. C 2007, 111 (25), 8884-8891 DOI: 10.1021/jp067460k.

(53) Yan, X.; He, G.; Wu, X.; Benziger, J. Ion and Water Transport in 
Functionalized PEEK Membranes. J. Memb. Sci. 2013, 429, 13-22 DOI:

10.1016/j.memsci.2012.11.026.

(54) Meier, F.; Eigenberger, G. Transport Parameters for the Modelling of Water Transport in Ionomer Membranes for PEM-Fuel Cells. Electrochim. Acta 2004, 49 (11), 1731-1742 DOI: 10.1016/j.electacta.2003.12.004.

(55) Lamas, E. J.; Balbuena, P. B. Molecular Dynamics Studies of a Model Polymer-Catalyst-Carbon Interface. Electrochim. Acta 2006, 51 (26), 59045911 DOI: 10.1016/j.electacta.2006.03.033.

(56) Hibbs, M. R.; Hickner, M. A.; Alam, T. M.; McIntyre, S. K.; Fujimoto, C. H.; Cornelius, C. J. Transport Properties of Hydroxide and Proton Conducting Membranes. Chem. Mater. 2008, 20 (7), 2566-2573 DOI: $10.1021 / \mathrm{cm} 703263 \mathrm{n}$.

(57) Disabb-Miller, M. L.; Johnson, Z. D.; Hickner, M. A. Ion Motion in Anion and Proton-Conducting Triblock Copolymers. Macromolecules 2013, 46 (3), 949956 DOI: $10.1021 / \mathrm{ma301947t.}$

(58) Hibbs, M. R.; Fujimoto, C. H.; Cornelius, C. J. Synthesis and Characterization of Poly(phenylene)-Based Anion Exchange Membranes for Alkaline Fuel Cells. Macromolecules 2009, 42 (21), 8316-8321 DOI: 10.1021/ma901538c.

(59) Vogt, B. D.; Soles, C. L.; Lee, H. J.; Lin, E. K.; Wu, W. L. Moisture Absorption and Absorption Kinetics in Polyelectrolyte Films: Influence of Film Thickness. Langmuir 2004, 20 (28), 1453-1458 DOI: 10.1021/la035239i.

(60) Ionic Conductivity and Diffusion at Infinite Dilution. In CRC Handbook of 
Chemistry and Physics; Rumble, J. R., Ed.; CRC Press/Taylor \& Francis: Boca Raton, FL.

(61) Duan, Q.; Ge, S.; Wang, C. Water Uptake, Ionic Conductivity and Swelling Properties of Anion-Exchange Membrane. J. Power Sources 2013, 243, 773778 DOI: 10.1016/j.jpowsour.2013.06.095.

(62) Dekel, D. R.; Rasin, I.; Page, M.; Brandon, S. Steady State and Transient Simulation of Anion Exchange Membrane Fuel Cells. J. Power Sources 2018, 375, 191-204 DOI: http://dx.doi.org/10.1016/j.jpowsour.2017.07.012.

(63) Dekel, D. R.; Willdorf, S.; Ash, U.; Amar, M.; Pusara, S.; Dhara, S.; Srebnik, S.; Diesendruck, C. E. The Critical Relation between Chemical Stability of Cations and Water in Anion Exchange Membrane Fuel Cells Environment. $J$. Power Sources 2018, 375, 351-360 DOI: 10.1016/j.jpowsour.2017.08.026.

(64) Kusoglu, A.; Kienitz, B. L.; Weber, A. Z. Understanding the Effects of Compression and Constraints on Water Uptake of Fuel-Cell Membranes. $J$. Electrochem. Soc. 2011, 158 (12), B1504-B1514 DOI: 10.1149/2.097112jes.

(65) Satterfield, M. B. Mechanical And Water Sorption Properties Of Nafion And Composite Nafion/Titanium Dioxide Membranes For Polymer Electrolyte Membrane Fuel Cells, Princeton, 2007.

(66) Follain, N.; Roualdes, S.; Marais, S. Water Transport Properties of PlasmaModified Commercial Anion- Exchange Membrane for Solid Alkaline Fuel Cells. J. Phys. Chem. C 2012, 116, 8510-8522 DOI: dx.doi.org/10.1021/jp2109835 . 
(67) Janarthanan, R.; Horan, J. L.; Caire, B. R.; Ziegler, Z. C.; Yang, Y.; Zuo, X.; Liberatore, M. W.; Hibbs, M. R.; Herring, A. M. Understanding Anion Transport in an Aminated Trimethyl Polyphenylene with High Anionic Conductivity. J. Polym. Sci. Part B Polym. Phys. 2013, 51 (24), 1743-1750 DOI: $10.1002 /$ polb.23164.

(68) Pandey, T. P.; Sarode, H. N.; Yang, Y. Y.; Yang, Y. Y.; Vezzù, K.; Noto, V. Di; Seifert, S.; Knauss, D. M.; Liberatore, M. W.; Herring, A. M. A Highly Hydroxide Conductive, Chemically Stable Anion Exchange Membrane, Poly(2,6 Dimethyl 1,4 Phenylene Oxide)- B -Poly(vinyl Benzyl Trimethyl Ammonium), for Electrochemical Applications. J. Electrochem. Soc. 2016, 163 (7), H513--H520 DOI: 10.1149/2.0421607jes.

(69) Chen, D.; Hickner, M. A. Ion Clustering in Quaternary Ammonium Functionalized Benzylmethyl Containing Poly(arylene Ether Ketone)s. Macromolecules 2013, 46 (23), 9270-9278 DOI: 10.1021/ma401620m.

(70) Ponce-Gonzalez, J.; Whelligan, D. K.; Wang, L.; SOUALHI, R.; Wang, Y.; Peng, Y.; Peng, H.; Apperley, D. C.; Sarode, H. N.; Pandey, T. P.; Divekar, A. G.; Seifert, S. S. S.; Herring, A. M.; Zhuang, L.; Varcoe, J. R.; PonceGonzález, J.; Whelligan, D. K.; Wang, L.; Bance-Soualhi, R.; Wang, Y.; Peng, Y.; Peng, H.; Apperley, D. C.; Sarode, H. N.; Pandey, T. P.; Divekar, A. G.; Seifert, S. S. S.; Herring, A. M.; Zhuang, L.; Varcoe, J. R.; Ponce-Gonzalez, J.; Whelligan, D. K.; Wang, L.; Bance-Soualhi, R.; Wang, Y.; Peng, Y.; Peng, H.; Apperley, D. C.; Sarode, H. N.; Pandey, T. P.; Divekar, A. G.; Seifert, S. S. S.; 
Herring, A. M.; Zhuang, L.; Varcoe, J. R. High Performance AliphaticHeterocyclic Benzyl-Quaternary Ammonium Radiation-Grafted AnionExchange Membranes. Energy Environ. Sci. 2016, 3724-3735 DOI: 10.1039/C6EE01958G.

(71) Pandey, T. P.; Maes, A. M.; Sarode, H. N.; Peters, B. D.; Lavina, S.; Vezzù, K.; Yang, Y.; Poynton, S. D.; Varcoe, J. R.; Seifert, S.; Liberatore, M. W.;

Noto, V. Di; Herring, A. M. Interplay between Water Uptake, Ion Interactions, and Conductivity in an E-Beam Grafted Poly(ethylene-Co-Tetrafluoroethylene) Anion Exchange Membrane. Phys. Chem. Chem. Phys. Phys. Chem. Chem. Phys 2015, 17 (17), 4367-4378 DOI: 10.1039/c4cp05755d.

(72) Mangiagli, P. M.; Ewing, C. S.; Xu, K.; Wang, Q.; Hickner, M. a. Dynamic Water Uptake of Flexible Ion-Containing Polymer Networks. Fuel Cells 2009, 9 (4), 432-438 DOI: 10.1002/fuce.200800157.

(73) Wright, A. G.; Holdcroft, S. Hydroxide-Stable Ionenes. ACS Macro Lett. 2014, 3 (5), 444-447 DOI: 10.1021/mz500168d.

(74) Ponce-Gonzalez, J.; Whelligan, D. K.; Wang, L.; SOUALHI, R.; Wang, Y.; Peng, Y.; Peng, H.; Apperley, D. C.; Sarode, H. N.; Pandey, T. P.; Divekar, A. G.; Seifert, S.; Herring, A.; Zhuang, L.; Varcoe, J. R. High Performance Aliphatic-Heterocyclic Benzyl-Quaternary Ammonium Radiation-Grafted Anion-Exchange Membranes. Energy Environ. Sci. 2016, 3724-3735 DOI: 10.1039/C6EE01958G.

(75) Kusoglu, A.; Kwong, A.; Clark, K. T.; Gunterman, H. P.; Weber, A. Z. Water 
Uptake of Fuel-Cell Catalyst Layers. 2012, 159 (9), 530-535 DOI:

10.1149/2.031209jes.

(76) Caire, B. R.; Vandiver, M. A.; Liberatore, M. W. Mechanical Testing of Small, Thin Samples in a Humidity-Controlled Oven. Rheol. Acta 2015, 54 (4), 253261 DOI: 10.1007/s00397-014-0834-7.

(77) Alix, S.; Colasse, L.; Morvan, C.; Lebrun, L.; Marais, S. Pressure Impact of Autoclave Treatment on Water Sorption and Pectin Composition of Flax Cellulosic-Fibres. Carbohydr. Polym. 2014, 102 (1), 21-29 DOI:

10.1016/j.carbpol.2013.10.092.

(78) Marais, S.; Métayer, M.; Nguyen, T. Q.; Labbé, M.; Perrin, L.; Saiter, J. M. Permeametric and Microgravimetric Studies of Sorption and Diffusion of Water Vapor in an Unsaturated Polyester. Polymer (Guildf). 2000, 41 (7), 2667-2676 DOI: 10.1016/S0032-3861(99)00434-6.

(79) Yang, Y.; Chun, M. S. The Effect of Chain Stiffness on Moisture Diffusion in Polymer Hydrogel by Applying Obstruction-Scaling Model. Korea Aust.

Rheol. J. 2013, 25 (4), 267-271 DOI: 10.1007/s13367-013-0027-4.

(80) Pandey, T. P.; Sarode, H. N.; Yang, Y.; Yang, Y.; Vezzù, K.; Noto, V. Di;

Seifert, S.; Knauss, D. M.; Liberatore, M. W.; Herring, A. M. A Highly Hydroxide Conductive, Chemically Stable Anion Exchange Membrane, Poly(2,6 Dimethyl 1,4 Phenylene Oxide)- B -Poly(vinyl Benzyl Trimethyl Ammonium), for Electrochemical Applications. J. Electrochem. Soc. 2016, 163 (7), H513-H520 DOI: 10.1149/2.0421607jes. 
(81) Vandiver, M. A.; Caire, B. R.; Pandey, T. P.; Li, Y.; Seifert, S.; Kusoglu, A.; Knauss, D. M.; Herring, A. M.; Liberatore, M. W. Effect of Hydration on the Mechanical Properties and Ion Conduction in a Polyethylene-B-

Poly(vinylbenzyl Trimethylammonium) Anion Exchange Membrane. J. Memb. Sci. 2016, 497, 67-76 DOI: 10.1016/j.memsci.2015.09.034.

(82) Feng, H. Modeling of Vapor Sorption in Glassy Polymers Using a New Dual Mode Sorption Model Based on Multilayer Sorption Theory. Polymer (Guildf). 2007, 48 (10), 2988-3002 DOI: 10.1016/j.polymer.2006.10.050.

(83) Detallante, V.; Langevin, D.; Chappey, C.; Métayer, M.; Mercier, R.; Pinéri, M. Water Vapor Sorption in Naphthalenic Sulfonated Polyimide Membranes. J. Memb. Sci. 2001, 190 (2), 227-241 DOI: 10.1016/S0376-7388(01)00437-9.

(84) Romero, T.; Mérida, W. Water Transport in Liquid and Vapour Equilibrated Nafion $^{\mathrm{TM}}$ Membranes. J. Memb. Sci. 2009, 338 (1-2), 135-144 DOI: 10.1016/j.memsci.2009.04.018.

(85) Wright, A. G.; Fan, J.; Britton, B.; Weissbach, T.; Lee, H.-F.; Kitching, E. A.; Peckham, T. J.; Holdcroft, S. Hexamethyl-P-Terphenyl Poly(benzimidazolium): A Universal Hydroxide-Conducting Polymer for Energy Conversion Devices. Energy Environ. Sci. 2016, 9 (6), 2130-2142 DOI: 10.1039/C6EE00656F.

(86) Caire, B. R.; Vandiver, M. A.; Pandey, T. P.; Herring, A. M.; Liberatore, M. W. Accelerated Mechanical Degradation of Anion Exchange Membranes via Hydration Cycling. J. Electrochem. Soc. 2016, 163 (10), H964-H969 DOI: 
10.1149/2.0771610jes.

(87) Ertem, S. P.; Caire, B. R.; Tsai, T. H.; Zeng, D.; Vandiver, M. A.; Kusoglu, A.;

Seifert, S.; Hayward, R. C.; Weber, A. Z.; Herring, A. M.; Coughlin, E. B.;

Liberatore, M. W. Ion Transport Properties of Mechanically Stable Symmetric

ABCBA Pentablock Copolymers with Quaternary Ammonium Functionalized

Midblock. J. Polym. Sci. Part B Polym. Phys. 2017, 55 (7), 612-622 DOI:

10.1002/polb.24310.

(88) Vandiver, M. A.; Caire, B. R.; Carver, J. R.; Waldrop, K.; Hibbs, M. R.;

Varcoe, J. R.; Herring, A. M.; Liberatore, M. W. Mechanical Characterization

of Anion Exchange Membranes by Extensional Rheology under Controlled

Hydration. J. Electrochem. Soc. 2014, 161 (10), H677-H683 DOI:

10.1149/2.0971410jes.

(89) Vandiver, M. A.; Caire, B. R.; Ertem, S. P.; Tsai, T.-H.; Coughlin, E. B.;

Herring, A. M.; Liberatore, M. W. Mechanical Performance of Polyiosoprene

Copolymer Anion Exchange Membranes by Varying Crosslinking Methods. $J$.

Electrochem. Soc. 2015, 162 (4), H206-H212 DOI: 10.1149/2.0471504jes.

(90) Omasta, T. J.; Wang, L.; Peng, X.; Lewis, C. A.; Varcoe, J. R.; Mustain, W. E. Importance of Balancing Membrane and Electrode Water in Anion Exchange Membrane Fuel Cells. J. Power Sources 2017 DOI:

10.1016/j.jpowsour.2017.05.006.

(91) Dekel, D. R.; Amar, M.; Willdorf, S.; Kosa, M.; Dhara, S.; Diesendruck, C. E. Effect of Water on the Stability of Quaternary Ammonium Groups for Anion 
Exchange Membrane Fuel Cell Applications. Chem. Mater. 2017, 29 (10), 4425-4431 DOI: 10.1021/acs.chemmater.7b00958.

(92) Harley, S. J.; Glascoe, E. A.; Maxwell, R. S. Thermodynamic Study on Dynamic Water Vapor Sorption in Sylgard-184. J. Phys. Chem. B 2012, 116 (48), 14183-14190 DOI: 10.1021/jp305997f.

(93) Zhao, Q.; Majsztrik, P.; Benziger, J. Diffusion and Interfacial Transport of Water in Nafion. J. Phys. Chem. B 2011, 115 (12), 2717-2727 DOI: 10.1021/jp1112125.

(94) Majsztrik, P. W.; Satterfield, M. B.; Bocarsly, A. B.; Benziger, J. B. Water Sorption, Desorption and Transport in Nafion Membranes. J. Memb. Sci. 2007, 301 (1-2), 93-106 DOI: 10.1016/j.memsci.2007.06.022.

(95) Crank, J. The Mathematics of Diffusion, 2nd ed.; Oxford University Press: Oxford, 1975.

(96) Fink, D.; Behar, M. Transport Processes : Fundamentals. In Transport Processes in Ion-Irradiated Polymers; Springer-Verlag Berlin Heidelberg, 2004; pp 3-46.

(97) Gebel, G.; Lyonnard, S.; Mendil-Jakani, H.; Morin, A. The Kinetics of Water Sorption in Nafion Membranes: A Small-Angle Neutron Scattering Study. $J$. Phys. Condens. Matter 2011, 23 (23), 234107 DOI: 10.1088/0953$8984 / 23 / 23 / 234107$

(98) Mecheri, B.; Felice, V.; Zhang, Z.; D’Epifanio, A.; Licoccia, S.; Tavares, A. C. DSC and DVS Investigation of Water Mobility in Nafion/zeolite Composite 
Membranes for Fuel Cell Applications. J. Phys. Chem. C 2012, 116 (39), 20820-20829 DOI: 10.1021/jp301762h.

(99) Hallinan, D. T.; Elabd, Y. A. Diffusion of Water in Nafion Using TimeResolved Fourier Transform Infrared-Attenuated Total Reflectance Spectroscopy. J. Phys. Chem. B 2009, 113 (13), 4257-4266 DOI: 10.1021/jp811325v.

(100) Rivin, D.; Kendrick, C. E.; Gibson, P. W.; Schneider, N. S. Solubility and Transport Behavior of Water and Alcohols in Nafion ${ }^{\mathrm{TM}}$. Polymer (Guildf). 2001, 42 (2), 623-635 DOI: 10.1016/S0032-3861(00)00350-5.

(101) Krtil, P. Kinetics of Water Sorption in NafionThin Films - Quartz Crystal Microbalance Study. J. Phys. Chem. B 2001, No. 105, 7979-7983 DOI: 10.1021/jp004162t.

(102) Burgess, S. K.; Mikkilineni, D. S.; Yu, D. B.; Kim, D. J.; Mubarak, C. R.; Kriegel, R. M.; Koros, W. J. Water Sorption in Poly(ethylene Furanoate) Compared to Poly(ethylene Terephthalate). Part 2: Kinetic Sorption. Polym. (United Kingdom) 2014, 55 (26), 6870-6882 DOI:

10.1016/j.polymer.2014.10.065.

(103) Krueger, K. M.; Sadowski, G. Fickian and Non-Fickian Sorption Kinetics of Toluene in Glassy Polystyrene. Macromolecules 2005, 38 (20), 8408-8417 DOI: $10.1021 / \mathrm{ma} 050353 \mathrm{o}$. 